\title{
Brazilian Group of Gastrointestinal Tumours' consensus guidelines for the management of oesophageal cancer
}

\author{
Duilio R Rocha-Filho ${ }^{1,2}$, Renata D’Alpino Peixoto ${ }^{3}$, Rui F Weschenfelder ${ }^{4}$, Juliana F M Rego ${ }^{5}$, Rachel Riechelmann 6 , Anelisa K Coutinho7, \\ Gustavo S Fernandes ${ }^{8}$, Alexandre A Jacome ${ }^{3}$, Aline C Andrade ${ }^{3}$, Andre M Murad ${ }^{9}$, Celso A L Mello ${ }^{6}$, Diego S C G Miguel7, Diogo B D Gomes ${ }^{10}$, \\ Douglas J Racy ${ }^{11}$, Eduardo D Moraes ${ }^{3}$, Eduardo H Akaishi ${ }^{12}$, Elisangela S Carvalho ${ }^{13}$, Evandro S Mello ${ }^{12}$, Fauze Maluf Filho ${ }^{12}$, \\ Felipe J F Coimbra ${ }^{6}$, Fernanda C Capareli ${ }^{8}$, Fernando F Arruda ${ }^{8}$, Fernando M A C Vieira ${ }^{14}$, Flavio R Takeda ${ }^{12}$, Guilherme C C Cotti ${ }^{8}$, \\ Guilherme L S Pereira ${ }^{15}$, Gustavo A Paulo ${ }^{16}$, Héber S C Ribeiro 6 , Laercio G Lourenco ${ }^{16}$, Marcela Crosara ${ }^{2}$, Marcelo G Toneto ${ }^{17}$, \\ Marcos B Oliveira ${ }^{18}$, Maria de Lourdes Oliveira ${ }^{2}$, Maria Dirlei Begnami ${ }^{6}$, Nora M Forones ${ }^{16}$, Osmar Yagi ${ }^{12}$, Patricia Ashton-Prolla ${ }^{19}$, \\ Patricia B Aguillar ${ }^{20}$, Paulo C G Amaral7, Paulo M Hoff ${ }^{2}$, Raphael L C Araujo ${ }^{16}$, Raphael P Di Paula Filho ${ }^{20}$, Rene C Gansl ${ }^{3}$, Roberto A Gil ${ }^{3}$, \\ Tulio E F Pfiffer ${ }^{8}$, Tulio Souza ${ }^{21}$, Ulysses Ribeiro Jr. ${ }^{12}$, Victor Hugo F Jesus ${ }^{6}$, Wilson L Costa Jr ${ }^{6}$ and Gabriel Prolla ${ }^{3}$
}

\author{
${ }^{1}$ Hospital Universitário Walter Cantídio, 60430-372 Fortaleza, Brazil \\ ${ }^{2}$ Grupo Oncologia D’Or, 04535-110 São Paulo, Brazil \\ ${ }^{3}$ Grupo Oncoclínicas, 04543-906 São Paulo, Brazil \\ ${ }^{4}$ Hospital Moinhos de Vento, 90035-000 Porto Alegre, Brazil \\ ${ }^{5}$ Hospital Universitário Onofre Lopes, 59012-300 Natal, Brazil \\ ${ }^{6} \mathrm{AC}$ Camargo Cancer Center, 01525-001 Sao Paulo, Brazil \\ ${ }^{7}$ Clínica AMO, 41.950-640 Salvador, Brazil \\ ${ }^{8}$ Hospital Sírio Libanês, 01308-050 São Paulo, Brazil \\ 'Laboratório Personal, 30130-090 Fortaleza, Brazil \\ ${ }^{10}$ Hospital Israelita Albert Einstein, 05652-900, São Paulo, Brazil \\ ${ }^{11}$ Hospital Beneficência Portuguesa de São Paulo, 01323-001 São Paulo, Brazil \\ ${ }^{12}$ Faculdade de Medicina da Universidade de São Paulo, 01246903 São Paulo, Brazil \\ ${ }^{13}$ Hospital São Rafael, 41253-190 Salvador, Brazil \\ ${ }^{14}$ Américas Oncologia, 22775-001 Rio de Janeiro, Brazil \\ ${ }^{15}$ Centro de Oncologia do Paraná, 81200-100 Curitiba, Brazil \\ 16 Universidade Federal de São Paulo, 04040-003 São Paulo, Brazil \\ ${ }^{17}$ Hospital São Lucas da PUCRS, 90610-000 Porto Alegre, Brazil \\ ${ }^{18}$ Faculdade de Ciências Médicas da Santa Casa de São Paulo, 01238-010 São Paulo, Brazil \\ ${ }^{19}$ Hospital de Clínicas de Porto Alegre, 90035-903 Porto Alegre, Brazil \\ ${ }^{20}$ Hospital Alemão Oswaldo Cruz, 01323-020 São Paulo, Brazil \\ ${ }^{21}$ Hospital Aliança de Salvador, 41920-900 Salvador, Brazil
}

\section{Abstract}

Oesophageal cancer is among the ten most common types of cancer worldwide. More than $80 \%$ of the cases and deaths related to the disease occur in developing countries. Local socio-economic, epidemiologic and healthcare particularities led us to create a Brazilian guideline for the management of oesophageal and oesophagogastric junction (OGJ) carcinomas. The Brazilian Group of Gastrointestinal Tumours invited 50 physicians with different backgrounds, including radiology, pathology, endoscopy, nuclear medicine, genetics, oncological surgery, radiotherapy and clinical oncology, to collaborate. This document was prepared based on an extensive review of topics related to heredity, diagnosis, staging, pathology, endoscopy, surgery, radiation, systemic therapy (including checkpoint inhibitors) and follow-up, which was followed by presentation, discussion and
Correspondence to: Duilio R Rocha-Filho Email: duilio.rocha@gmail.com

ecancer 2021, 15:1195

https://doi.org/10.3332/ecancer.2021.1195

Published: 02/03/2021

Received: 11/07/2020

Copyright: $@$ the authors; licensee ecancermedicalscience. This is an Open Access article distributed under the terms of the Creative Commons Attribution License (http:// creativecommons.org/licenses/by/3.0), which permits unrestricted use, distribution, and reproduction in any medium, provided the original work is properly cited. 
voting by the panel members. It provides updated evidence-based recommendations to guide clinical management of oesophageal and OGJ carcinomas in several scenarios and clinical settings.

Keywords: oesophageal cancer, gastroesophageal cancer, guidelines

\section{Introduction}

Oesophageal cancer is among the ten most common types of cancer worldwide. More than $80 \%$ of the cases and deaths related to the disease occur in developing countries. It is usually about three to four times more common in males than in females, although high mortality rates in both genders are observed [1]. In Brazil, the National Cancer Institute estimates 11,390 new oesophageal cancer cases in each year of 2020-2022 triennium [2]. Oesophageal cancer is usually diagnosed in advanced stages, presenting locoregional invasion or distant metastasis, which makes the prognosis particularly poor in most cases.

\section{Objective}

The Brazilian Group of Gastrointestinal Tumours (GTG) organised this report aiming to consolidate the opinion of Brazilian specialists on specific topics related to the diagnosis, staging and treatment of oesophageal cancer. This document was prepared based on an extensive review of each item, followed by the presentation, discussion and voting by the panel members. It provides updated evidence-based recommendations to guide clinical management of oesophageal and oesophagogastric junction OGJ carcinomas. However, GTG emphasises that the clinical judgment of the physician must prevail as the patient individuality is a critical aspect of medical examination.

\section{Panel composition}

A panel of 50 physicians with different backgrounds, including radiology, pathology, endoscopy, nuclear medicine, genetics, oncological surgery, radiotherapy and clinical oncology, were invited to collaborate. All experts are involved in the practice of the diagnosis, management and treatment of patients with oesophageal cancer. Considering the regional diversity of Brazil, the GTG invited specialists from various regions, including representatives from Bahia, Ceara, Federal District, Minas Gerais, Rio Grande do Norte, Rio Grande do Sul, Rio de Janeiro and Sao Paulo. All members of the panel followed the recommendations of the Federal Council of Medicine concerning disclosure of potential conflicts of interest.

\section{The methodology used to develop the consensus}

Topics were organised by the GTG and distributed among members a few months in advance of presentation and voting. All specialists did a comprehensive literature review, following the GTG's standard guidelines on how each topic should be addressed. All panel members were instructed to describe the level of evidence and strength of recommendation, as shown in Table 1. During the face-to-face meeting, the participants presented a summary of each of the reviewed topics, followed by discussion and voting when no consensus was reached. In this report, the recommendations on different subjects may guide the clinical management in several scenarios and clinical settings. In specific topics, the recommendation may point out the lack of unanimity about the level of evidence or strength of recommendation.

\section{Disclaimer}

All recommendations were constructed upon scientific evidence. Readers must contextualise each recommendation according to the technology availability in their clinical routine. 
Table 1. Level of evidence and strength of recommendation. CDC classification system.

\begin{tabular}{|c|l|}
\hline I & $\begin{array}{l}\text { Evidence of at least one large randomised controlled trial (RCT), of good methodological quality (low potential for bias) or meta-analyses of well- } \\
\text { conducted randomised clinical trials without heterogeneity }\end{array}$ \\
\hline II & $\begin{array}{l}\text { RCTs }{ }^{\text {a }} \text { small or large RCTs } \\
\text { geneity }\end{array}$ \\
\hline III & Prospective cohort studies \\
\hline IV & Retrospective cohort studies or case-control studies (low methodological quality) or meta-analyses of these tests or tests with demonstrated hetero- \\
\hline V & Studies without a control group, case reports and expert opinions \\
\hline
\end{tabular}

${ }^{a}$ RCTs, Randomised clinical trials

\begin{tabular}{|c|l|}
\hline A & Solid evidence of efficacy with substantial clinical advantage - strongly recommended \\
\hline B & Strong or moderate evidence, in terms of effectiveness, but with a limited clinical benefit - generally recommended \\
\hline C & Insufficient evidence of effectiveness or benefit does not outweigh risks/disadvantages (i.e. adverse events or costs) - optional \\
\hline D & Moderate evidence against effectiveness or evidence indicating adverse outcomes - generally not recommended \\
\hline E & Strong evidence against effectiveness or indicating adverse outcomes - not recommended \\
\hline
\end{tabular}

\section{Topics discussed}

\section{Heredity}

When to suspect hereditary syndromes in oesophageal cancer and OGJ and how to assess the patient?

There is no substantial evidence to support the investigation of hereditary syndromes in oesophageal cancer [3].

\section{Staging}

What tests are necessary for the diagnosis and staging of oesophageal cancer and OGJ?

\section{Recommendations}

- Upper digestive endoscopy (UDE) with biopsy is the gold standard for the diagnosis of oesophageal cancer. EVIDENCE LEVEL I, RECOMMENDATION A.

- Computed tomography (CT) of the chest and abdomen with intravenous contrast should be carried out. It is unnecessary if positron emission tomography-CT (PET/CT) is already carried out. EVIDENCE LEVEL I, RECOMMENDATION A.

- CT of the pelvis should be carried out, if clinically indicated. EVIDENCE LEVEL I, RECOMMENDATION A.

- PET is a preferable test in the absence of M1 disease (PET-CT is preferred over PET). EVIDENCE LEVEL II, RECOMMENDATION B.

- In the absence of M1 disease, an echoendoscopy can be carried out with a fine needle biopsy when indicated. EVIDENCE LEVEL I, RECOMMENDATION A.

- There is little evidence to support the indication of echoendoscopy after neoadjuvant therapy. EVIDENCE LEVEL II, RECOMMENDATION C.

- Laparoscopy is optional in patients with an OGJ tumour (in the absence of M1 disease). EVIDENCE LEVEL III, RECOMMENDATION B.

- Bone scintigraphy for T3N1 can be considered if PET is not available. EVIDENCE LEVEL III, RECOMMENDATION C.

- Bronchoscopy is indicated for tumours at or above the tracheal bifurcation. EVIDENCE LEVEL III, RECOMMENDATION B.

- The main objective of the initial patient evaluation is to determine whether the disease can be resected with curative intent. 
UDE with biopsy is essential for the diagnosis and staging of the neoplasia. The Siewert tumour type should be assessed in all patients with adenocarcinomas involving the OGJ. Tumours whose epicentre is located within 1-5 cm above the anatomic OGJ are classified as Siewert type I. Siewert type II is defined as a carcinoma with the tumour epicentre located within $1 \mathrm{~cm}$ above and $2 \mathrm{~cm}$ below the OGJ. Tumours whose epicentre is located between 2 and $5 \mathrm{~cm}$ below the OGJ are defined as Siewert III and should be managed in accordance with the gastric cancer guidelines [4].

The next step is to carry out a multidetector CT of the chest and abdomen, which allows reconstruction in multiple planes [5]. If metastatic disease is not detected in CT scans, PET should be carried out. PET-CT detects up to $20 \%$ more distant metastasis in comparison to CT. PETCT displays a superior diagnostic performance than PET in the metastasis screening. Also, PET-CT may lead to a change in the stage of disease in up to $40 \%$ of all cases. However, its pooled sensitivity for the detection of locoregional metastases was only 0.51 (95\% confidence interval $(\mathrm{Cl})=0.34-0.69)$ in a systematic review of 12 studies, since regional nodes are often obscured by the metabolic activity of primary tumour [6].

If metastatic disease or regional lymph node involvement is not diagnosed on CT or PET-CT, echoendoscopy to assess regional lymph nodes can be considered [7-11]. Echoendoscopy is the exam with the highest sensitivity and specificity for $T$ and $N$ staging of oesophageal and gastric cardia tumours. When an echoendoscopic assessment of the oesophagus is possible over the entire extent of the organ, the sensitivity of staging can reach $92 \%$ for the tumour and $88 \%$ for lymph node involvement [11].

However, echoendoscopy works better in the advanced rather than in the early stage of the disease. In a meta-analysis of 49 studies, pooled sensitivity to diagnose $\mathrm{T} 1$ and $\mathrm{T} 4$ tumours was $81.6 \%(95 \% \mathrm{Cl}=77.8-84.9)$ and $92.4 \%(95 \% \mathrm{Cl}=89.2-95.0)$, respectively [12]. Furthermore, the echoendoscopic discrimination between mucosal (T1a) and submucosal (T1b) lesions, which is important to select patients for endoscopic treatment, is only $80 \%$ accurate [13]. Endoscopic resection provides accurate information on the depth of tumour invasion and should be considered for early-stage tumours ( $(\mathrm{CT} 1 \mathrm{a}$ and $\mathrm{cT} 1 \mathrm{~b} \leq 2 \mathrm{~cm}$ ) [13]. Some other conditions related to decreased accuracy of echoendoscopic staging are stenosis of the upper portion of the oesophagus (sensitivity $28 \%$ for tumours and $72 \%$ for lymph nodes assessment) [14] and previous neoadjuvant treatment (sensitivity $69 \%$ and specificity $52 \%$ for lymph nodes assessment). Therefore, whenever possible, carrying out echoendoscopy before neoadjuvant therapy is recommended [15].

We recommend bronchoscopy for tumours located at or above the carina in the initial staging, which can help in both surgery and radiotherapy treatments $[16,17]$. A prospective study showed that even in tumours located below the tracheal bifurcation, bronchoscopy identified airway invasion in $6.5 \%$ of otherwise potentially operable patients [18].

In cases of malignant stenosis, we recommend dilation before echoendoscopy whenever possible to improve staging. This management may have an impact on up to $20 \%$ of the patients $[19,20]$. Known tumour markers have no role in the diagnosis, staging or monitoring of patients with oesophageal and gastric cardia cancer.

\section{Pathology}

\section{How should oesophageal tumours be histologically classified?}

\section{Recommendation}

- Histopathology studies of oesophageal tumours should follow the classification of the World Health Organization (WHO). EVIDENCE LEVEL I, RECOMMENDATION A.

Squamous cell carcinoma and adenocarcinoma correspond to approximately $95 \%$ of oesophageal cancer. Temporal trends in incidence vary for the two major histologic types of oesophageal cancer. Squamous cell carcinoma has become less common in several Western countries because of long-term reductions in tobacco use and alcohol consumption, and now accounts for less than $30 \%$ of all oesophageal cancers in the United States and Western Europe [2]. Although a rise in the incidence of adenocarcinoma has also been observed in Brazil, squamous cell carcinoma remains the most common histology in the country [2]. A cross-sectional study of 24,204 patients with oesophageal cancer registered between 2001 and 2010 in Brazilian hospital-based registries showed that 82\% of the oesophageal cancer cases were squamous 
cell carcinomas, compared to only $9 \%$ of adenocarcinomas [21]. Among 565 patients with oesophageal carcinoma treated at a single centre in São Paulo between 2009 and 2011, 19\% had the diagnosis of adenocarcinoma and 81\% had squamous cell carcinomas [22].

Squamous cell carcinoma differs from the adenocarcinoma in several aspects, including epidemiology, tumour biology and clinical evolution. Currently, squamous cell carcinoma and adenocarcinomas are considered distinct entities.

According to the WHO's report published in 2010 [23], oesophageal epithelial cancer is classified into the following:

- Squamous cell carcinoma;

- Verrucous carcinoma;

- Spindle cell carcinoma;

- Adenocarcinoma;

- Undifferentiated carcinoma;

- Mucoepidermoid carcinoma;

- Adenoid cystic carcinoma;

- Small cell carcinoma;

- Adenosquamous carcinoma;

When describing squamous cell, verrucous and spindle cell (squamous) carcinomas and adenocarcinoma subtypes, the tumour should be graded according to its degree of cell differentiation. Thus, the tumour can be classified as:

- Grade I: well-differentiated

- Grade II: moderately differentiated

- Grade III: poorly differentiated

Grade classification is not necessary for mucoepidermoid, adenoid cystic, small cell, adenosquamous and undifferentiated carcinomas, as the degree of differentiation is already implicit in each of these subtypes.

\section{Which information is critical in the histopathological study of oesophageal cancer?}

\section{Recommendations}

- Location and the disease extension. RECOMMENDATION A.

- Histological type. RECOMMENDATION A.

- Degree of differentiation. RECOMMENDATION A.

- Level of lymphatic, venous or perineural invasion. RECOMMENDATION A.

- The total number of dissected lymph nodes and the number of affected lymph nodes. RECOMMENDATION A.

- The margin status. RECOMMENDATION A.

- Staging according to tumour-node-metastasis (TNM) criteria. RECOMMENDATION A.

Concerning location and extension of the disease, the 8th edition of the AJCC staging manual24 divides oesophageal cancer into cervical, upper thoracic, middle thoracic, lower and abdominal thoracic and OGJ, defined as the tubular oesophagus attached to the stomach, and is measured from the top of the gastric folds. Tumours located in the cervical oesophagus are classified as cancer of the upper thoracic oesophagus. The abdominal oesophagus includes the lower thoracic oesophagus. Tumours involving the OGJ that have an epicentre within $2 \mathrm{~cm}$ proximal to the cardia or proximal to stomach should be classified as oesophageal cancer. Tumours whose epicentre is more than $2 \mathrm{~cm}$ from the OGJ (Siewert III) should be classified as gastric cancer, and therefore follow gastric TNM parameters for staging [24]. This reflects epidemiological findings that indicate that the prognosis of patients with oesophageal cancer and OGJ is correlated to T staging, histology, degree of differentiation and tumour location [25]. For data reporting purposes, Barrett's oesophagus showing high-grade dysplasia in an oesophageal resection should be reported as in situ carcinoma. 
Table 2. Ryan's modified system for therapeutic response.

\begin{tabular}{|l|c|}
\hline \multicolumn{1}{|c|}{ Description } & Score \\
\hline No viable cancer cells (complete response) & 0 \\
\hline Isolated cells or rare small groups of cancer cells (almost complete response) & 1 \\
\hline Residual cancer with evident tumour regression, however, with more than single cells or rare small groups of cancer cells (partial response) & 2 \\
\hline Extensive residual cancer without evident tumour regression (low or no response) & 3 \\
\hline
\end{tabular}

The margins are segmented into proximal, distal and radial. The circumferential resection margin (CRM) represents the soft tissue closest to the deepest penetration of the tumour. The sections for evaluating the margins of the proximal and distal resections can be obtained in two orientations [24] as follows:

1. Facial sections parallel to the margin;

2. Longitudinal sections perpendicular to the margin.

The choice of the section impacts the analysis of the margin status. The distance from the tumour margin to the nearest resection margin should be measured if not compromised by invasive carcinoma. The proximal and distal resection margins should be assessed for Barrett's oesophagus and squamous and glandular dysplasia if they are not compromised by invasive carcinoma [24].

Tumours resected by endoscopy are evaluated at the vertical margin. The lateral margins can be considered relevant in cases where the endoscopic dissection of submucosa was carried out in complete resection samples [24].

Adequate resection requires obtaining satisfactory margins, including the circumferential margin [26]. The definition of a positive CRM depends on the pathological reporting system used. The College of American Pathologists defines a positive CRM as the presence of tumour at the resection margin [27], whereas the United Kingdom Royal College of Pathologists defines a positive CRM as the presence of oesophageal cancer within $1 \mathrm{~mm}$ of the margin [28].

How to grade the histological response to neoadjuvant treatment of oesophageal cancer and OGJ?

\section{Recommendation}

- The therapeutic response must consider the percentage of viable neoplastic cells. RECOMMENDATION A.

The determination of the percentage of viable cells and the classification of non-viable cells, such as necrosis, fibrosis and mucus, is a reliable method to assess the tumour's response [29]. Additionally, the 8th Edition of AJCC recommends the use of Ryan's modified method, which has demonstrated good interobserver reproducibility and has prognostic value in rectal cancer [24] (Table 2). Also, the verification of lymph node remission corroborates the information of tumour response and provides relevant prognostic data, especially for those with a high response rate of the primary tumour [30].

\section{What is the minimum number of lymph nodes to be evaluated by the pathologist in the surgical specimen?}

\section{Recommendation}

- An assessment of at least 15 lymph nodes should be considered on the surgical specimen of oesophageal cancer. RECOMMENDATION A.

The extension of lymphadenectomy during the surgery of oesophageal cancer is of considerable debate. The minimum number of lymph nodes that should be resected has not been described in the literature. However, pieces of evidence associate better survival rates with more extended lymphadenectomies [31]. The enhancement of the accuracy in N staging requires the evaluation of 15 lymph nodes. It is important to note that the number of assessed lymph nodes impacts the accuracy of the pathology analysis. Therefore, resection of as many lymph nodes as possible is recommended. 
When and how should biomarkers be evaluated in gastric, oesophageal and OGJ cancer?

\section{Recommendations}

- In biopsies of localised OGJ or oesophageal adenocarcinomas, the assessment of HER2 status is optional. EVIDENCE LEVEL V, RECOMMENDATION C.

- In biopsies of metastatic adenocarcinomas of the OGJ or oesophagus, with the intention of palliative treatment, HER2 status should be investigated. EVIDENCE LEVEL I, RECOMMENDATION A.

- The assessment of HER2 status in metastatic adenocarcinomas of the OGJ or oesophagus can be made in surgical specimens, biopsies or cell blocks of primary or metastatic tumours, by using immunohistochemistry and interpreted according to the recommended scoring system. Borderline cases (++) in immunohistochemistry must be confirmed by FISH test. EVIDENCE LEVEL I, RECOMMENDATION A.

- The evaluation of MSI should be carried out on samples of advanced oesophageal and OGJ carcinomas. EVIDENCE LEVEL III, RECOMMENDATIONA.

- The assessment of MSI should be carried out on samples of early stage OGJ adenocarcinoma. EVIDENCE LEVEL IV, RECOMMENDATION B.

- Programmed cell death ligand 1 (PD-L1) assessment should be carried out on samples of advanced oesophageal and OGJ carcinomas. EVIDENCE LEVEL I, RECOMMENDATION A.

- Neurotrophic Tyrosine Receptor Kinase (NTRK) fusions testing should be carried out in advanced oesophageal and OGJ carcinomas. EVIDENCE LEVEL III, RECOMMENDATION A.

Overexpression of the growth factor receptor HER2 is reported in a subgroup of 7\%-30\% of patients with gastric and oesophageal adenocarcinoma. HER2 is a member of the HER family, which encompasses several growth factor receptors, including HER1, HER3 and HER4, all involved in the regulation of cell growth, proliferation and survival [32].

The rate of HER2 positivity in oesophageal adenocarcinoma varies considerably, but it may be slightly higher than in gastric carcinomas. In general, the overexpression of HER2 in oesophageal adenocarcinoma correlates with a worse prognosis. Different studies point to a correlation between HER2 overexpression and greater depth of tumour invasion, lymph node involvement, distant metastases and low survival rates [33].

The assessment of the status of HER2 is critical to define which patients with advanced disease could benefit from the use of trastuzumab. HER2 analysis can be carried out on surgical specimens, biopsies and cell blocks [34] (primary or metastatic tumour). Hofman et al [35] published a validated scoring system for assessing HER2 status in gastric cancer (Table 3).

Table 3. Score system for HER2 assessment in gastric and gastroesophageal adenocarcinoma.

\begin{tabular}{|c|c|l|l|l|}
\hline Score & $\begin{array}{c}\text { Microscope } \\
\text { magnification }\end{array}$ & \multicolumn{1}{|c|}{ Staining pattern of surgical specimen } & \multicolumn{1}{c|}{$\begin{array}{c}\text { Staining pattern of biopsy } \\
\text { assessment }\end{array}$} \\
\hline 0 & $40 \times$ & $\begin{array}{l}\text { No reactivity or membranous reactivity in } \\
<10 \% \text { of tumour cells }\end{array}$ & $\begin{array}{l}\text { Absence of reactivity or absence of membranous } \\
\text { reactivity }\end{array}$ & Negative \\
\hline $1+$ & $40 \times$ & $\begin{array}{l}\text { Subtle or barely detectable membranous reac- } \\
\text { tivity in } \geq 10 \% \text { of tumour cells. Reactivity only in } \\
\text { part of the cell membrane }\end{array}$ & $\begin{array}{l}\text { Group of tumour cells with subtle or barely notable } \\
\text { membrane reactivity, regardless of the percentage } \\
\text { of reactive cells }\end{array}$ & Negative \\
\hline $2+$ & $10-20 \times$ & $\begin{array}{l}\text { Weak to moderate membranous reactivity, } \\
\text { complete, basal lateral or lateral in } \geq 10 \% \text { of } \\
\text { tumour cells }\end{array}$ & $\begin{array}{l}\text { Group of tumour cells with weak to moderate } \\
\text { complete basolateral or lateral membrane reactivity, } \\
\text { regardless of the percentage of reactive cells }\end{array}$ & $\begin{array}{l}\text { Undetermined (need } \\
\text { confirmation with FISH } \\
\text { or SISH) }\end{array}$ \\
\hline $3+$ & $2.5-5 \times$ & $\begin{array}{l}\text { Strong and complete membranous reactivity, } \\
\text { basolateral or lateral in } \geq 10 \% \text { of tumour cells }\end{array}$ & $\begin{array}{l}\text { Group of tumour cells with membranous reactivity, } \\
\text { basolateral or lateral independently of the reactive } \\
\text { cells' percentage }\end{array}$ & Positive \\
\hline
\end{tabular}

SISH: silver-enhanced in situ hybridization; HER: human epidermal growth factor receptor; FISH: fluorescence in situ hybridization 
The immediate fixation of approximately 20-30 minutes in buffered formalin is fundamental to histopathological analysis [36]. It is noteworthy that, in gastric and OGJ adenocarcinoma, the positivity of HER2 in the cell membrane found in immunohistochemistry tests is lateral and basal. No staining of the luminal surface of the cells can be observed. For diagnosis purposes in surgical specimens, it used to be necessary to find more than $10 \%$ of HER2 positive cells in the specimen. This criterion is, however, considered inadequate today, and the recommendation for diagnosis in surgical resection specimens should be the same for biopsy studies. A sample with a cluster of five positive cells is sufficient for diagnosis [35, 36].

During endoscopy, as many samples as possible of the suspected cancer lesion should be collected. It is recommended to obtain at least six samples to increase the accuracy, since false-negative results may occur if the amount of tissue is not adequate or minimal [36].

MSI is characterised by changes in regions with repeated DNA sequences (microsatellites), resulting from mutational inactivation or epigenetic silencing of DNA repair genes (for example, MSH1, MSH2, MSH6 and MLH1). This is the primary cause of genetic instability observed in tumours. Neoplasms with MSI can stimulate the immune system, becoming susceptible to immunotherapy with the use of checkpoint inhibitors. Furthermore, OGJ adenocarcinomas with MSI seem less sensitive to perioperative chemotherapy [37]. However, there is no consensus about the best technique to test the presence of MSI. There is a high correlation between polymerase chain reaction and immunohistochemistry, and no significant difference has been found between them [38].

For oesophageal, OGJ and gastric tumours, PD-L1 expression should be determined by using the combined positive score (CPS) instead of tumour proportion score (TPS). CPS is the number of PD-L1 staining cells (tumour cells, lymphocytes and macrophages) divided by the total number of viable tumour cells and multiplied by 100 . When compared to TPS, CPS is a more sensitive prognostic biomarker in these tumour types [39].

Although generally rare, $N T R K$ gene fusions are oncogenic drivers of various adult and paediatric tumours, including oesophageal and OGJ carcinomas. Several methods have been used to detect NTRK gene fusions including immunohistochemistry, FISH, reverse transcriptase polymerase chain reaction (RT-PCR), and DNA- or RNA-based next-generation sequencing, as described elsewhere [40].

\section{Endoscopic resection}

\section{When to consider endoscopic resection in oesophageal cancer or OGJ?}

\section{Recommendations}

- In patients with T1a tumours, oesophagectomy or endoscopic resection can be carried out to remove tumours locally. EVIDENCE LEVEL III, RECOMMENDATION A.

- Patients with a well-differentiated oesophageal or OGJ tumour limited to the epithelium or to the lamina propria should be treated with endoscopic resection. EVIDENCE LEVEL III, RECOMMENDATION A.

- In oesophageal tumours T1b, oesophagectomy is the primary treatment. EVIDENCE LEVEL I, RECOMMENDATION A.

Early oesophageal cancer is defined as high-grade dysplasia (previously called carcinoma in situ) or T1 carcinoma. T1 is divided into T1a (up to the mucosa muscle) and T1b (up to the submucosa) [41].

Cancer of the mucosa (T1a) includes high-grade dysplasia carcinoma in situ (T1am1) and tumours infiltrating the lamina propria (T1am2) or muscularis mucosa (T1am3). Submucosal carcinoma can be classified as T1bsm1, T1bsm2 or T1bsm3, depending on the invasion in the upper, middle or lower third of the submucosa in the surgical specimen $[42,43]$ or invasion of the superficial submucosa (less than $200 \mu \mathrm{m}$ of the muscularis mucosa for squamous cell carcinoma and less than $500 \mu \mathrm{m}$ for adenocarcinomas) [44].

The depth of the lesion in superficial oesophageal adenocarcinoma has a significant clinical value. In cases of superficial tumours limited to SM2, the probability of lymph node involvement is $11 \%$ and increases with the extension of the lesion in the mucosa [45]. Patients with SM3 tumours should be managed with oesophagectomy [46]. There is no consensus on the best therapeutic option in the treatment of early oesophageal tumours. Endoscopic resection certainly has fewer morbidity rates than oesophagectomy, although one may admit the possibility of recurrence. It is crucial that the pathological specimens are fixed adequately for pathology analysis. 


\section{Non-metastatic disease: surgery for oesophageal cancer and OGJ}

What are the surgical options for the initial or early stages of oesophageal cancer and OGJ?

\section{Recommendations}

- Patients with mucosa-limited oesophageal tumours (Tis or T1a) can be treated with endoscopic resection. EVIDENCE LEVEL III, RECOMMENDATION A.

- In patients with superficial oesophageal tumours (T1a), oesophagectomy or endoscopic resection can be carried out. EVIDENCE LEVEL III, RECOMMENDATION A.

- In T1bNO or T2N0 oesophageal tumours, oesophagectomy is the first treatment option. EVIDENCE LEVEL I, RECOMMENDATION A.

- Oesophagectomy should be carried out in referral centres and by an experienced surgeon. EVIDENCE LEVEL IV, RECOMMENDATION A.

- Minimally invasive oesophagectomy has shown similar efficacy with less surgical complications and may be preferred over open approaches. EVIDENCE LEVEL I, RECOMMENDATION A.

Surgical mortality associated with oesophagectomy is lower in referral centres, with a large annual volume of major surgeries. The amount of surgeries per surgeon is also directly associated with mortality rates related to oesophagectomy [47, 48]. Thus, we recommend an experienced surgeon in a specialised reference centre to carry out an open or minimally invasive oesophagectomy. Different thresholds to define low- and high-volume institutions have been used, so that it is hard to establish a clear cut-off point [49]. Metzger et al [50] showed that a significant reduction of perioperative mortality can be achieved in centres that carry out more than 20 oesophagectomies per year.

Oesophagectomy has significantly higher morbidity and mortality than other highly complex surgeries. The 5-year survival rate for operated oesophageal cancer is about $20 \%$, and the impact of surgical complications should always be considered. The prognostic factors with the most considerable influence on mortality and postoperative survival are R0 resection and lymph node staging [51]. The current data from squamous cell carcinoma suggest that a minimum proximal and distal margin of $3.5-5 \mathrm{~cm}$ is needed to decrease the risk of local recurrence. For adenocarcinoma of the oesophagus, the adequate margins are less clearly defined [52].

Minimally invasive surgery in early oesophageal cancer (via thoracoscopy) aims to reduce postoperative morbidity and mortality and may be a potentially advantageous alternative. It must follow the same oncological principles as open oesophagectomy, without compromising longterm survival and providing a better quality of life for the patient.

Several studies support the use of minimally invasive oesophagectomies. A randomised trial showed that patients undergoing minimally invasive oesophagectomy had a lower rate of pulmonary infections compared with patients treated with open oesophagectomy (12\% versus 34\%; relative risk $0.35 ; 95 \% \mathrm{Cl}=0.16-0.78$ ) [53]. No differences in disease-free or overall survival between arms were found. Another randomised trial compared robot-assisted minimally invasive thoracolaparoscopic oesophagectomy (RAMIE) with open oesophagectomy. RAMIE resulted in significant lower complications, better quality of life and better functional recovery, with similar oncological outcomes [54]. Accordingly, a French controlled trial found that hybrid minimally invasive oesophagectomy resulted in lower incidence of major complications than open oesophagectomy, without compromising overall and disease-free survival [55]. Furthermore, different meta-analyses support the safety and efficacy of minimally invasive surgery [56-59].

\section{Non-metastatic disease - chemotherapy and radiotherapy in oesophageal and OGJ cancer}

\section{When and which neoadjuvant treatment should be indicated to oesophageal or OGJ cancer?}

\section{Recommendations}

Adenocarcinoma cT2 cNO:

- Perioperative chemotherapy is preferably the treatment of choice. EVIDENCE LEVEL I, RECOMMENDATION A.

- Upfront surgery is also an alternative. EVIDENCE LEVEL I, RECOMMENDATION B. 
- Combined chemoradiotherapy with carboplatin and paclitaxel is another option. EVIDENCE LEVEL I, RECOMMENDATION B.

Squamous cell carcinoma cT2NO:

- Combining chemoradiotherapy with carboplatin and paclitaxel is preferably the treatment of choice. EVIDENCE I, RECOMMENDATION A.

- Upfront surgery is also an alternative. EVIDENCE I, RECOMMENDATION B.

Adenocarcinoma T3-T4a and/or N+:

- Either combined chemoradiotherapy with carboplatin and paclitaxel or perioperative chemotherapy are recommended. EVIDENCE I, RECOMMENDATION A.

- Preoperative chemoradiotherapy may be preferred in patients with Siewert I tumours, those with higher risk of positive margins or more susceptible to severe treatment-related adverse events. EVIDENCE V, RECOMMENDATION C

- Perioperative chemotherapy may be preferred in the management of Siewert III tumours, in patients with higher risk of distant relapse, such as those with multiple positive nodes, in patients who need rapid palliation of dysphagia or who have difficult access to radiation therapy. EVIDENCE V, RECOMMENDATION C

- FLOT is the preferred perioperative chemotherapy regimen for patients with good performance status. EVIDENCE I, RECOMMENDATION A.

- Perioperative chemotherapy with cisplatin and 5 -fluorouracil (CF) is also a valid option, as well as oxaliplatin-based doublets FOLFOX or CAPOX. EVIDENCE I, RECOMMENDATION B.

- Induction chemotherapy followed by chemoradiotherapy may also be considered. EVIDENCE II, RECOMMENDATION C.

Squamous cell carcinoma T3-T4a and/or N+:

- Chemoradiotherapy with carboplatin and paclitaxel is recommended. EVIDENCE I, RECOMMENDATION A.

\section{Induction chemotherapy followed by surgery}

The theoretical advantages of this approach include better chances of tumour resection and reduced regional and distant micrometastases. Documented clinical response rates vary from $40 \%$ to $65 \%$; the proportion of complete pathological response varies from $0 \%$ to $10 \%$; and resectability rates range from $40 \%$ to $80 \%$ [60-65]. To date, there are four large prospective randomised, phase III studies comparing induction chemotherapy, followed by surgery versus isolated surgery in patients with locally advanced oesophageal cancer. In these studies, the 5 -year survival rate varied between $23 \%$ and $38 \%$ in groups that were treated with chemotherapy, followed by surgery versus $17 \%-24 \%$ in groups of patients undergoing isolated surgery [66-70]. Two meta-analyses suggest a more significant benefit of induction chemotherapy in patients with squamous cell carcinoma versus adenocarcinoma [71, 72].

\section{Neoadjuvant chemoradiotherapy}

The poor long-term prognosis and the sensitising effect of cytotoxic agents on radiation led several researchers to evaluate chemoradiotherapy in the preoperative (neoadjuvant) setting. There are at least ten prospective, randomised, phase III studies that compare concomitant chemoradiotherapy, followed by surgery with isolated surgery in patients with potentially resectable oesophageal carcinoma [73-82]. Among these studies, the most important are the Dutch CROSS trial and CALGB 9781 trial [80, 83].

In the CROSS trial, Dutch researchers randomised 368 patients with potentially resectable oesophageal or OGJ carcinoma to receive preoperative chemoradiotherapy with paclitaxel $50 \mathrm{mg} / \mathrm{m}^{2}$ associated with carboplatin (area under the curve $=2$ ) and concomitant radiation therapy (41.4 Gy for 5 weeks) or surgery alone. In this study, $75 \%$ of the patients had adenocarcinoma and $23 \%$ had squamous cell carcinoma. Besides, most patients had disease located in the third distal of the oesophagus or OGJ (82\% of the patients). R0 resection rates were higher in patients undergoing neoadjuvant chemoradiotherapy (92\% versus 69\%), and $29 \%$ of those who received neoadjuvant treatment achieved a complete pathological response. After a median follow-up of 45.4 months, the median survival of patients receiving concomitant neoadjuvant chemoradiotherapy was statistically superior than in the group treated with surgery alone (49.4 months versus 24.0 months; hazard 
ratio $(\mathrm{HR})=0.657 ; p=0.003)[83,84]$. An alternative regimen with 5-fluorouracil $(5-\mathrm{FU})$ and cisplatin is optional in services where paclitaxel and carboplatin are not available [85].

CALGB 9781 was designed as a randomised trial of trimodal therapy versus surgery in 500 patients with oesophageal or OGJ cancer with stage I-III. Because of low recruitment, the study was closed prematurely, with only 56 patients included. Although the result is not statistically significant, 5-year survival rate was $39 \%$ versus $16 \%$ in favour of trimodal therapy [80].

There is only one phase III study that compares chemoradiotherapy with chemotherapy in the neoadjuvant setting in patients with OGJ adenocarcinoma. The German POET trial randomised 126 patients to 16 weeks of chemotherapy alone (cisplatin and 5-FU/leucovorin) versus 12 weeks of the same chemotherapy, followed by radiotherapy concomitant with cisplatin and etoposide. Both groups underwent subsequent surgical resection. The rate of complete pathological response was significantly superior in the group that received chemoradiotherapy (16\% versus $2 \%$ ). Likewise, a trend towards better survival in 3 years was observed in this group (47\% versus 28\%; $p=0.07$ ). The POET findings support the neoadjuvant chemoradiotherapy strategy for patients with OGJ adenocarcinoma. However, it is essential to note that the study closed prematurely and, therefore, is underpowered to show consistent survival benefit [86].

Several meta-analyses that address the possible differences between neoadjuvant treatments and surgery alone in the two histological types of oesophageal carcinoma were published. In 2011, Kranzfelder et al [87] reported meta-analysis results that included 20 trials addressing neoadjuvant chemoradiotherapy or chemotherapy versus surgery alone. $\mathrm{HR}$ for overall survival was $0.81(95 \% \mathrm{Cl}=0.70-0.95 ; p=0.008)$ after chemoradiotherapy and $0.93(95 \% \mathrm{Cl}=0.81-1.08 ; p=0.368)$ after chemotherapy. Also, better R0 resection rates were observed with the two types of neoadjuvant therapy without increasing morbidity and mortality [87].

When investigating the same groups of patients, an updated meta-analysis that included 4,188 cases published by Sjoquist et al [88] showed reduced mortality with neoadjuvant chemoradiotherapy $(\mathrm{HR}=0.78 ; 95 \% \mathrm{Cl}=0.70-0.88 ; p<0.0001)$, which means a survival benefit of $8.7 \%$ in 2 years, or a need to treat 11 patients to prevent one death. The benefit was similar in all histological subtypes (HR $=0.80$ for squamous cell carcinoma; $95 \% \mathrm{Cl}=0.68-0.93 ; p=0.004$ and $\mathrm{HR}=0.75$ for adenocarcinoma; $95 \% \mathrm{Cl}=0.59-0.95 ; p=0.02)$. The HR for the overall indirect comparison of all-cause mortality for neoadjuvant chemoradiotherapy versus neoadjuvant chemotherapy was $0.88(95 \% \mathrm{Cl}=0.76-1.01 ; p=$ 0.07) [88]. The benefit of concomitant chemoradiotherapy in oesophageal cancer is overwhelming. However, the need for surgery in patients who achieve a complete pathological response is still under debate.

A new approach to better select patients for chemoradiotherapy uses the PET/CT assessment. A phase II study evaluated early response with PET/CT after induction chemotherapy in 257 patients. Patients with oesophageal and OGJ adenocarcinoma with no response to the first neoadjuvant chemotherapy regimen received another chemotherapy regimen aiming to improve the complete pathological response. This strategy, however, still needs confirmation [34].

\section{Perioperative chemotherapy}

Oesophageal adenocarcinoma and squamous cell carcinoma behave as two distinct disease entities regarding epidemiological aspects, pathogenesis, natural history and prognosis.

Some authors consider that distal oesophageal, OGJ and gastric adenocarcinoma have the same biological response, and therefore share the treatment principles. Upon this reasoning, in 2006, the phase III MAGIC trial was published. The study randomly assigned 503 patients with resectable adenocarcinoma of the stomach, OGJ or lower oesophagus to three preoperative and three postoperative cycles of ECF regimen (epirubicin, cisplatin and 5-FU) or surgery alone. In 11\% and 15\% of the patients, the tumour site was in distal oesophagus and OGJ, respectively. Although only $42 \%$ of the patients completed the proposed treatment, an increase in both progression-free survival (HR $=0.66$; $95 \%$ $\mathrm{Cl}=0.53-0.81 ; p<0.001)$ and overall survival $(\mathrm{HR}=0.75 ; 95 \% \mathrm{Cl}=0.60-0.93 ; p=0.009)$ was observed in favour of the group undergoing perioperative chemotherapy. The $25 \%$ reduction in the risk of death resulted in an increase in 5 -year overall survival from $23 \%$ to $36 \%$. In a subgroup analysis, the treatment benefited all patients, independently of the primary tumour site [67]. In line with these findings, the French study FNCLCC/FFCD, published in 2011, randomised 224 patients with adenocarcinoma of the distal oesophagus ( $n=25$ ), OGJ ( $n=144$ ) and stomach $(n=55)$ to receive perioperative chemotherapy with cisplatin and 5-FU regimen for two to three cycles, followed by surgery, and then three to four cycles of postoperative chemotherapy versus surgery alone. Only $50 \%$ of the patients in the experimental group received at least one postoperative chemotherapy cycle. Some authors observed a benefit in both progression-free survival in 5 years (34\% versus 
$19 \% ; \mathrm{HR}=0.65 ; p=0.003$ ) and overall survival in 5 years (38\% versus $24 \% ; \mathrm{HR}=0.69 ; p=0.02)$ in favour of perioperative chemotherapy arm. Therefore, considering these two trials, perioperative chemotherapy is a solid option for patients with lower oesophageal adenocarcinoma and OGJ [70].

More recently, the German phase III FLOT4-AIO study randomised 716 patients to three preoperative cycles, followed by three postoperative cycles of ECF/ECX (epirubicin $50 \mathrm{mg} / \mathrm{m}^{2}$, cisplatin $60 \mathrm{mg} / \mathrm{m}^{2}$, on both D1 and 5-FU $200 \mathrm{mg} / \mathrm{m}^{2}$ as a continuous infusion or oral capecitabine $1,250 \mathrm{mg} / \mathrm{m}^{2}$ D1-21) every 3 weeks, or four preoperative cycles, followed by four postoperative cycles of FLOT (docetaxel 50 $\mathrm{mg} / \mathrm{m}^{2}$, oxaliplatin $85 \mathrm{mg} / \mathrm{m}^{2}$, leucovorin $200 \mathrm{mg} / \mathrm{m}^{2}$ and $5-\mathrm{FU} 2600 \mathrm{mg} / \mathrm{m}^{2}$ in a 24-hour infusion in D1) every 2 weeks. The primary endpoint was overall survival. Patients with gastric or OGJ adenocarcinoma (56\% of the total patients) with stage $\geq \mathrm{cT} 2$ and or N+ were eligible. FLOT regimen improved median overall survival from 35 months (ECF/ECX arm) to 50 months with a median follow-up of 43 months [89]. As shown in this study, FLOT supplanted the results of the previous MAGIC study and, therefore, when available and for fit patients, we recommend this scheme as the preferential neoadjuvant treatment modality.

Post-hoc analysis of MAGIC trial suggests that adjuvant or perioperative chemotherapy may not be helpful - and may even be deleterious - for oesophagogastric cancer patients with MSI. Although controversial, the MSI status may be used to select patients for perioperative treatment [37].

Some Asian studies have investigated the role of preoperative or perioperative chemotherapy in patients with squamous cell carcinoma. Adjuvant chemotherapy with cisplatin and fluorouracil was shown to increase disease-free survival over surgery alone, especially in the subgroup with lymph node metastasis, in the JCOG9204 randomised trial [90]. Subsequently, the JCOG9907 trial randomised patients with clinical stage II or III squamous cell carcinoma to undergo surgery, followed by two courses of cisplatin plus 5-FU, as in JCOG9204, or preceded by the same regimen. Preoperative treatment significantly increased 5-year overall survival (43\% versus 55\%) [91]. In Japan, preoperative chemotherapy is recommended for clinical stages II or III thoracic oesophageal cancer patients, based on data from the JCOG9907 study [92]. However, the role of preoperative or perioperative chemotherapy in squamous cell carcinoma is not defined in Western patients. Therefore, this panel does not recommend its use.

Both preoperative chemoradiotherapy and perioperative chemotherapy are reasonable options for the management of oesophageal adenocarcinoma T3-T4a and/or N+. Some patient and tumour characteristics may help defining the best treatment option. Chemoradiotherapy is commonly associated with higher cytotoxic activity than chemotherapy alone [86], although experimental arms in FLOT and CROSS trials have shown similar complete pathologic response rates in the adenocarcinoma population [83, 89]. In patients in need of cytoreduction and at risk of positive margins, including Siewert I tumours, the addition of radiotherapy is commonly considered. Acute toxicity data favour CROSS regimen over FLOT [83, 89], so that preoperative chemoradiation may be favoured in patients more susceptible to severe treatmentrelated adverse events. On the other hand, longer and more intense FLOT regimen is believed to be systemically more active than shortduration weekly carboplatin-paclitaxel used in the CROSS trial. Indeed, the impact of CROSS regimen in reducing distant metastasis seems to disappear over time [84]. In patients with higher risk of distant relapse, such as those with multiple nodes, perioperative FLOT may be preferred. FLOT may also be favoured in patients in need of rapid palliation of dysphagia or who have difficult access to radiotherapy centres.

\section{When should adjuvant immunotherapy be indicated to oesophageal or OGJ cancer?}

\section{Recommendation}

- Adjuvant nivolumab may be considered in patients with resected stage II/III oesophageal or OGJ cancer who received neoadjuvant chemoradiotherapy and have residual pathologic disease. EVIDENCE LEVEL II, RECOMMENDATION B.

CheckMate 577 is a phase III clinical trial that randomised patients who had pathologic residual disease after neoadjuvant chemoradiotherapy and RO surgical resection to nivolumab or placebo for up to 1 year. Adjuvant nivolumab showed an improvement in median diseasefree survival from 11.0 to 22.4 months $(\mathrm{HR}=0.69 ; 96.4 \% \mathrm{Cl}=0.56-0.86 ; p=0.0003)$ [93]. Benefit was seen irrespective of histology or tumour PD-L1 expression, as assessed by Dako 28-8 pharmDx assay. Some caution is needed when interpreting these results, since overall survival data are not mature and median follow-up time is only 24 months. Updated data will be of great importance. Nevertheless, adjuvant nivolumab may be considered if available. 
When considered, what type of radiotherapy is recommended for patients with oesophageal or OGJ cancer?

\section{Recommendations}

- In patients with oesophageal cancer (adenocarcinoma or epidermoid) stage T3-4a and/or N + M0, we recommend neoadjuvant chemoradiotherapy with carboplatin and paclitaxel, followed by surgery. EVIDENCE LEVEL I, RECOMMENDATION A.

- The total radiation dose is 41.4 Gy. EVIDENCE LEVEL I, RECOMMENDATION A.

- Definitive chemoradiotherapy is acceptable when surgery is not a good option considering performance status and comorbidity for patients with oesophageal adenocarcinoma with T3-4b and/or N+ MO stages. EVIDENCE LEVEL II, RECOMMENDATION C.

- Definitive chemoradiotherapy is acceptable when surgery is not a good option considering performance status and comorbidity for patients with oesophageal squamous cell carcinoma with T3-4b and/or N+ M0 stages EVIDENCE LEVEL II, RECOMMENDATION B.

- Patients with T1b-4b N+ cervical oesophageal carcinoma may be treated with definitive chemoradiotherapy. EVIDENCE LEVEL IV, RECOMMENDATION B.

- Patients with adenocarcinoma stage T3-4a and/or N+ M0 may have surgery, followed by chemoradiotherapy. EVIDENCE LEVEL IV, RECOMMENDATION C.

- The chemotherapy regimen associated with radiotherapy for definitive chemoradiotherapy should preferably be composed of cisplatin and 5-FU. EVIDENCE LEVEL I, RECOMMENDATION B and paclitaxel and carboplatin EVIDENCE LEVEL II, RECOMMENDATION A.

- Chemotherapy associated with radiotherapy in stage T3-4b and/or N+ M0 oesophageal cancer may alternatively comprise oxaliplatin, irinotecan, docetaxel or capecitabine. EVIDENCE LEVEL III, RECOMMENDATION C.

What is the best treatment option for locally advanced non-resectable, non-metastatic oesophageal or OGJ cancer?

\section{Recommendations}

- Chemotherapy and radiotherapy can be indicated in selected patients with good performance status and in those who are inoperable or refuse surgery. EVIDENCE LEVEL II, RECOMMENDATION A.

- If the patient is not a candidate for definitive chemoradiotherapy, chemotherapy or palliative radiotherapy alone may be indicated. EVIDENCE LEVEL III, RECOMMENDATION B.

- The chemotherapy regimen associated with radiotherapy in unresectable locally advanced oesophageal cancer should preferably be carboplatin and paclitaxel. EVIDENCE LEVEL III, RECOMMENDATION A.

- Chemotherapy associated with radiation therapy in locally advanced oesophageal cancer may use, alternatively, platinum and fluoropyrimidine combination. EVIDENCE LEVEL I, RECOMMENDATION C.

- The total radiation dose is $50.4 \mathrm{~Gy}$ in the setting of definitive chemoradiotherapy non-resectable patients. EVIDENCE LEVEL I, RECOMMENDATION C.

The treatment of oesophageal cancer with locoregional invasion has evolved significantly in the past two decades. This topic addresses unresectable diseases for technical reasons due to a lack of clinical conditions or the patient's refusal to surgery. The low complete response rates after local therapy alone led to the incorporation of systemic chemotherapy into the treatment, in an attempt to control distant micrometastases and to potentiate the local effects of radiation.

\section{Definitive chemoradiotherapy (without surgery)}

Cytotoxic agents and radiation therapy are combined to promote better outcomes in patients with advanced oesophageal cancer. The current use of platinum and 5-FU with radiotherapy appears to have significant radiation sensitising effect [94, 95]. Other agents, such as taxanes and irinotecan, have also been investigated for the same purposes [96, 97].

Two prospective, randomised, phase III trials, conducted by cooperative research groups, compared definitive radiotherapy with definitive concomitant chemoradiotherapy in patients with locally advanced oesophageal cancer [85, 98]. The first study (RTOG 85-01) compared chemotherapy with cisplatin $\left(75 \mathrm{mg} / \mathrm{m}^{2}\right.$ on day 1 , weeks 1 and 5) and 5-FU (1,000 mg/m² per day, days 1-4 of weeks 1 and 5) concomitant with 
radiotherapy (50 Gy in 2 Gy per day, over 5 weeks) versus conventional radiation therapy (64 Gy in 2 Gy per day, over 6.5 weeks) in patients with thoracic oesophageal cancer and with locoregional invasion. The group of patients randomised to chemoradiotherapy also received two additional cycles of chemotherapy after the end of radiotherapy. Surgery was not part of the treatment regimens. This trial closed prematurely with only 121 patients after an interim analysis that demonstrated a significant survival benefit in chemoradiotherapy arm. Median survival was 12.5 months for the combined group and 8.9 months for the group with isolated radiation therapy $(p<0.001)$ [85].

The superiority of definitive concomitant chemoradiotherapy over radiotherapy alone was confirmed by a second study, carried out by Eastern Cooperative Oncology Group (ECOG), which compared chemotherapy with 5-FU and mitomycin-C concomitant to radiotherapy (60 Gy) with radiation therapy alone (60 Gy) [98].

In 2010, a meta-analysis that included 19 randomised trials compared the definitive chemoradiotherapy approach (concomitant or in sequence) with radiotherapy alone as a treatment for oesophageal cancer with locoregional invasion. Chemotherapy concomitant with radiotherapy provided a significant reduction in mortality $(\mathrm{HR}=0.73 ; 95 \% \mathrm{Cl}=0.64-0.84)$. The results of trials with sequential chemoradiotherapy did not show significant benefit in survival or local disease control. The absolute gain in survival rates from combination therapy compared to radiotherapy alone was $9 \%$ in 1 year and $4 \%$ in 2 years [99].

Despite the absence of phase III studies with carboplatin and paclitaxel similar to the CROSS study in unresectable oesophageal cancer, the acceptable toxicity profile has made this scheme preferred in this clinical setting.

\section{Radiation therapy alone}

The radiotherapy treatment alone for oesophageal cancer is usually reserved for unresectable tumours in patients with a poor performance status to receive chemotherapy. In general, radiation monotherapy results in a median survival ranging from 6 to 12 months and a 5-year survival rate of less than $10 \%$ [100, 101]. Also, in phase III trials, the rates of local failure reach 84\% [102, 103].

\section{Persistent or relapsed tumour after definitive chemoradiotherapy: salvage surgery}

\section{What is the role of salvage surgery?}

\section{Recommendation}

- Salvage surgery can be considered in selected patients with localised resectable oesophageal cancer after definitive chemoradiotherapy, if there is no distant recurrence. EVIDENCE LEVEL III, RECOMMENDATION B.

Two randomised trials did not identify a survival benefit of trimodal therapy over definitive chemoradiotherapy in squamous cell oesophageal cancer $[104,105]$. Both neoadjuvant therapy with planned surgery and definitive chemoradiotherapy, followed by close observation can be recommended for those patients [106]. However, the non-operative strategy is associated with increased locoregional recurrence (rates between $40 \%$ and $75 \%$ have been reported after definitive chemoradiation), whereas local relapse is uncommon after trimodal therapy [85, 107, 108].Sudo et al [109] reported that $23 \%$ of patients who received bimodal therapy at MD Anderson Cancer Centre had locoregionalonly relapse. Therefore, salvage surgery may be considered in a significant proportion of patients.

Long-term survival rate of 17\%-51\% after salvage oesophagectomy has been reported in several studies [108, 110-112]. In a large European multicentre study, patients submitted to salvage surgery had a 3-year overall survival of $40 \%$ and 3 -year disease-free survival of $32 \%$, with in-hospital mortality rate of $8 \%$ [108].

However, salvage surgery is an option for carefully selected patients, since salvage oesophagectomy is a more morbid operation than either primary oesophagectomy or planned oesophagectomy after neoadjuvant chemoradiotherapy [111]. A pooled analysis of eight studies showed that salvage surgery is associated with a significantly increased incidence of post-operative mortality, anastomotic leak, pulmonary complications and length of hospital stay, when compared to planned oesophagectomy [113].

Surgery should only be attempted if an R0 resection is technically feasible and after distant metastatic disease has been ruled out [108]. More advanced pathologic states (T3-4 or N+), persistent tumour or early relapse after chemoradiotherapy, higher doses of radiation ( $\geq 55 \mathrm{~Gy}$ ) and upper thoracic oesophageal tumours have been associated with worse outcomes after salvage oesophagectomy [110, 111]. 


\section{Metastatic disease of oesophageal and OGJ cancer}

What is the best first-line chemotherapy regimen for the treatment of squamous cell carcinoma of the oesophagus?

\section{Recommendations}

- First-line treatment with chemotherapy + pembrolizumab is recommended for patients with advanced squamous cell carcinoma and PD-L1 CPS $\geq 10$. EVIDENCE LEVEL II, RECOMMENDATION A.

- For patients with lower expression of PD-L1 (CPS < 10), the panel recommends using chemotherapy rather than chemotherapy + immunotherapy, until further data on the role of checkpoint inhibitors in this group are reported. EVIDENCE LEVEL II, RECOMMENDATION C.

- Although cisplatin plus fluorouracil is the most studied regimen to combine with pembrolizumab, the panel believes that the checkpoint inhibitor may also be combined with other fluoropyrimidine and platinum regimens, such as FOLFOX. EVIDENCE LEVEL V, RECOMMENDATION C.

- First-line chemotherapy with a fluoropyrimidine and platinum regimen is suggested if the addition of immunotherapy is not recommended or unavailable. EVIDENCE LEVEL III, RECOMMENDATION A.

- Three-drug cytotoxic regimens such as FLOT or modified DCF should be reserved for young patients with good performance status and high volume of disease. EVIDENCE LEVEL III, RECOMMENDATION B.

- For patients with metastatic squamous cell carcinoma of the oesophagus, incorporation of cetuximab into first-line treatment is not recommended. EVIDENCE LEVEL II, RECOMMENDATION D.

The therapeutic objective in patients with unresectable and/or metastatic oesophageal cancer is to palliate symptoms, including dysphagia, and to improve survival.

Most of the cytotoxic agents were tested in squamous cell carcinoma histology when this histology was predominant. For this reason, chemotherapy regimens for oesophageal cancer employed drugs frequently used in head and neck squamous cell carcinoma, including 5-FU, cisplatin, mitomycin, methotrexate and bleomycin, among others. Many groups adopted the combination of 5-FU and cisplatin as a standard regimen, and since then, studies have looked for a third agent that could add benefit to this regimen.

With the changes in epidemiology, treatments for advanced gastric cancer and oesophageal tumours converged, and thus, most clinical studies from the 1990s on began to include patients with gastric, oesophageal and OGJ cancer independently of the histology. The most important of those studies are described in GTG guidelines for gastric cancer [4].

Phase III KEYNOTE-590 evaluated the role of first-line immunotherapy in oesophageal cancer. The trial enrolled 749 patients with previously untreated advanced oesophageal carcinoma or OGJ Siewert I adenocarcinoma. Patients were randomised to chemotherapy alone (cisplatin +5 -FU for up to six cycles) or in combination with pembrolizumab (200 mg every 3 weeks for up to 35 cycles) [114]. About half the patients had PD-L1 CPS $\geq 10$ and 73\% of the patients had squamous cell carcinoma. In the interim analysis reported at ESMO 2020, median overall survival (12.4 versus 9.8 months; $\mathrm{HR}=0.73 ; 95 \% \mathrm{Cl}=0.62-0.86 ; p<0.0001$ ) and median progression-free survival (6.3 versus 5.8 months; $\mathrm{HR}=0.65 ; 95 \% \mathrm{Cl}=0.55-0.76 ; p<0.0001$ ) were superior in patients treated with pembrolizumab. Confirmed overall response rate was also higher in the experimental arm (45.0\% versus 29.3\%; $p$ <.0001). Subgroup analysis of KEYNOTE-590 showed that the benefit of pembrolizumab plus chemotherapy was seen irrespective of the histology (see 'Which are the first-line regimens recommended for HER2 negative oesophageal or OGJ adenocarcinoma?' below). Overall survival benefit was seen in the analysis of all included patients, but maximum benefit was observed in patients with CPS $\geq 10$. The efficacy of pembrolizumab is patients with CPS < 10 was not reported, so it is possible that high-PD-L1 expressors are inflating the overall survival benefit observed.

Which are the first-line regimens recommended for HER2 negative oesophageal or OGJ adenocarcinoma?

\section{Recommendations}

- For advanced oesophageal or OGJ adenocarcinomas with PD-L1 CPS $\geq 5$, first-line treatment with FOLFOX/CAPOX in association with nivolumab is recommended. EVIDENCE LEVEL II, RECOMMENDATION B. 
- Chemotherapy plus pembrolizumab is also an option if PD-L1 CPS $\geq 10$. EVIDENCE LEVEL II, RECOMMENDATION C.

- Although cisplatin plus fluorouracil is the most studied regimen to combine with pembrolizumab in oesophagogastric cancer, the panel believes that this checkpoint inhibitor may also be combined to other regimens, such as FOLFOX. EVIDENCE LEVEL V, RECOMMENDATION C.

- For patients with lower expression of PD-L1 (CPS < 5), the panel recommends using chemotherapy rather than chemotherapy + immunotherapy, until further data on the role of checkpoint inhibitors in this group are reported. EVIDENCE LEVEL II, RECOMMENDATION C.

- First-line chemotherapy with a fluoropyrimidine and platinum regimen or FOLFIRI is suggested if the addition of immunotherapy is not recommended or unavailable. EVIDENCE LEVEL I, RECOMMENDATION A.

- Three-drug cytotoxic regimens such as FLOT or modified DCF should be reserved for young patients with good performance status and high volume of disease. EVIDENCE LEVEL II, RECOMMENDATION B.

- First-line pembrolizumab monotherapy is an option for fragile patients or those with low tumour burden, particularly if PD-L1 CPS $\geq$ 10. EVIDENCE LEVEL II, RECOMMENDATION C.

- Reduced dose CAPOX or single-agent chemotherapy with fluoropyrimidine, irinotecan or paclitaxel are options for patients who are not candidates for aggressive treatment. EVIDENCE LEVEL II, RECOMMENDATION B.

- Immunotherapy alone or in combination with chemotherapy should be the preferential first-line treatment for patients with deficiency in mismatch repair (dMMR)/MSI-H tumours. EVIDENCE LEVEL III, RECOMMENDATION A.

Chemotherapy regimens indicated for metastatic oesophageal, OGJ or gastric adenocarcinoma and metastatic oesophageal squamous cell carcinoma are frequently interchangeably used, although with different levels of evidence. GTG recommendations for the treatment of advanced gastric adenocarcinoma are discussed in detail elsewhere [4].

Briefly, the preferred cytotoxic regimens for the treatment of oesophagogastric adenocarcinomas combine a fluoropyrimidine and a platinum agent. Different phase III trials showed interchangeability between infusional 5-FU and capecitabine and between cisplatin and oxaliplatin $[115,116]$. Irinotecan-based regimens such as FOLFIRI and irinotecan + cisplatin are also active as first-line therapy [117-121]. Three-drug cytotoxic regimens, such as DCF, FLOT and TEF, have shown conflicting results in randomised trials and should be reserved for fit patients with high volume of disease and with access to frequent toxicity evaluation [122-125]. A dose-modified DCF regimen improved overall survival with better tolerability in a randomised phase II trial and should be preferred over parental DCF [123]. Most centres abandoned the use of triplets with epirubicin because of the lack of significant benefit over doublets. Low-dose oxaliplatin + capecitabine was shown to be noninferior to full-dose regimen with better overall treatment utility, a composite of clinical benefit, tolerability, quality of life and patient value, in elderly or frail patients [126]. Therefore, reduced dose fluoropyrimidine + oxaliplatin is a reasonable treatment for patients considered unsuitable for intense chemotherapy. Single-agent chemotherapy with fluoropyrimidine, irinotecan or paclitaxel is also an option for patients who are not candidates for aggressive treatment.

Immunotherapy was incorporated into the treatment of gastroesophageal adenocarcinoma in the past few years and deserves further consideration. The role of nivolumab in the first-line setting was investigated in the phase III trials CheckMate 649 and ATTRACTION-4 [127, 128].In CheckMate 649, adults with previously untreated HER2-negative advanced oesophageal, OGJ or gastric adenocarcinomas were randomised to receive nivolumab $360 \mathrm{mg}$ every 3 weeks or $240 \mathrm{mg}$ every 2 weeks + chemotherapy (CAPOX or FOLFOX), chemotherapy alone or nivolumab + ipilimumab [127]. Nivolumab + ipilimumab arm was closed and enrolment continued on the other arms. Oesophageal and OGJ cancer patients represented $12 \%$ and $18 \%$ of the population, respectively. The primary endpoints were overall survival and progression-free survival in patients with PD-L1 CPS $\geq 5$. In a preliminary report, nivolumab + chemotherapy showed an improvement in overall survival (14.4 versus 11.1 months; $\mathrm{HR}=0.71(98.4 \% \mathrm{Cl}=0.59-0.86) ; p<0.0001)$ and progression-free survival $(7.7$ versus 6.1 months; HR $=0.68(98 \% \mathrm{Cl}=0.56-0.81) ; p<0.0001)$ when compared to chemotherapy alone in patients with PD-L1 CPS $\geq 5$. The addition of nivolumab to chemotherapy also increased response rate (45\% versus $60 \% ; p<0.0001)$. Statistically significant overall survival increase was also observed in patients with PD-L1 CPS $\geq 1$ and the all-randomised population. However, the benefit was smaller as PD-L1 expression decreased, so that the impact of nivolumab in patients with CPS 1-5 and, especially, in patients with PD-L1 0 is uncertain. Further analysis of biomarker selected patients is required to understand the value of nivolumab for all patients. In overall survival subgroup analysis, the impact 
of nivolumab was somewhat less impressive in oesophageal or OGJ adenocarcinoma ( $\mathrm{HR}=0.78$ and 0.84 , respectively) when compared to gastric cancer $(\mathrm{HR}=0.66)[127]$.

ATTRACTION-4 randomised 724 Asian patients with gastric or OGJ adenocarcinoma to receive nivolumab plus chemotherapy (S-1 + oxaliplatin or capecitabine + oxaliplatin) or placebo + chemotherapy [128]. The primary endpoints were centrally assessed progression-free survival and overall survival. At the interim analysis, median progression-free survival increased from 8.3 to 10.5 months in the experimental arm $(\mathrm{HR}=0.68 ; 98.51 \% \mathrm{Cl}=0.51-0.90 ; p=0.0007)$, but no overall survival difference was found $(\mathrm{HR}=0.90 ; 95 \% \mathrm{Cl}=0.75-1.08 ; p=0.257)$. Increased use of second-line treatment and of post-progression checkpoint inhibitors in ATTRACTION-4 patients, as compared to CheckMate 649, may help to justify the lack of overall survival benefit. PD-L1 expression evaluated by TPS did not predict benefit of nivolumab in ATTRACTION-4, in contrast to CPS used in CheckMate 649 or KEYNOTE-590 trials [114, 127, 128].The role of pembrolizumab, another anti-PD-1 monoclonal antibody, in gastroesophageal carcinoma was also evaluated in phase III trials. KEYNOTE-062 randomised 763 patients with untreated advanced gastric or OGJ adenocarcinoma with PD-L1 CPS $\geq 1$ to pembrolizumab 200 mg, pembrolizumab + chemotherapy (cisplatin + fluorouracil or capecitabine) or chemotherapy + placebo every 3 weeks [129]. OGJ adenocarcinoma represented about $30 \%$ of included patients. Primary endpoints were overall survival and progression-free survival in patients with PD-L1 CPS $\geq 1$ or $\geq 10$. In contrast to CheckMate 649, immunotherapy plus chemotherapy was not superior to chemotherapy plus placebo, irrespective of the magnitude of PD-L1 expression. On the other hand, interesting results were found in pembrolizumab monotherapy arm. The authors reported that pembrolizumab was non-inferior to chemotherapy for overall survival in patients with CPS $\geq 1$ (median 10.6 versus 11.1 months; $\mathrm{HR}=0.91$; $99.2 \% \mathrm{Cl}=0.69-1.18$ ), with better tolerability. In an exploratory analysis of patients with $\mathrm{CPS} \geq 10$, overall survival was numerically superior in pembrolizumab arm (median 17.4 versus 10.8 months; $\mathrm{HR}=0.69 ; 95 \% \mathrm{Cl}=0.49-0.97$ ), but this difference was not statistically tested [129]. First-line pembrolizumab monotherapy may be an option for carefully selected patients with PD-L1 expression. However, since short progression-free survival and low response rate were observed with pembrolizumab alone, that strategy may be restricted for fragile patients or those with low tumour burden, particularly if PD-L1 CPS $\geq 10$.

The KEYNOTE-590 trial observed an increase in overall survival in patients with oesophageal carcinoma treated with first-line chemotherapy plus pembrolizumab when compared to chemotherapy alone, particularly if CPS $\geq 10$ [114] (see 'What is the best first-line chemotherapy regimen for the treatment of squamous cell carcinoma of the oesophagus?' above). Subgroup analysis of KEYNOTE-590 showed that the benefit of pembrolizumab plus chemotherapy was seen irrespective of the histology. However, only $27 \%$ of the patients included in KEYNOTE-590 were adenocarcinomas, and previously discussed KEYNOTE-062 trial did not show impact of the addition of pembrolizumab to first-line chemotherapy in advanced gastroesophageal adenocarcinoma [129]. Therefore, the positive results of KEYNOTE-590 adenocarcinoma subgroup may be interpreted cautiously.

dMMR/MSI-H patients are overly sensitive to immunotherapy. Subset analyses of CheckMate 649 and KEYNOTE-062 trials suggest that the use of a checkpoint inhibitor in the treatment of MSI-H patients provides survival benefit over control [127, 129]. In previously described KEYNOTE-062, the survival benefit was enhanced with pembrolizumab (HR 0.29) and pembrolizumab plus chemotherapy (HR 0.37) versus chemotherapy in MSI-H patients [129]. The panel believes that immunotherapy alone or in combination with chemotherapy should be the preferential treatment for dMMR/MSI-H patients.

Which are the first-line regimens recommended for HER2 positive oesophageal, OGJ or advanced gastric adenocarcinoma?

\section{Recommendation}

- For patients with OGJ metastatic adenocarcinoma who have HER2 overexpression (3+ in IHC or FISH + or 2+ in IHC and confirmed by FISH+), it is recommended to use trastuzumab in the first-line chemotherapy regimen with a combination of platinum and fluoropyrimidine. EVIDENCE LEVEL I, RECOMMENDATION A.

The benefit of trastuzumab, an anti-HER2 monoclonal antibody, in adenocarcinomas of the stomach and OGJ, was evidenced in a phase III study called ToGA, which compared cisplatin and 5-FU/capecitabine regimens with and without trastuzumab (8 mg/kg in the first cycle and 6 $\mathrm{mg} / \mathrm{kg}$ in the remaining cycles). Objective response rates were significantly higher in the trastuzumab-treated group (47\% versus $35 \%$ ). After a median follow-up of 1.5-year, the median overall survival was also significantly superior in the trastuzumab-treated group (13.8 versus 11.1 months) [130]. 
Based on the TOGA trial, trastuzumab should be incorporated into the therapy of patients with gastric and OGJ adenocarcinoma who have overexpression of HER2. Considering that the biology background of metastatic oesophageal adenocarcinoma is very similar to metastatic adenocarcinomas of the OGJ and stomach, the use of trastuzumab should be extended to patients with these tumours.

Other anti-HER2 agents, such as pertuzumab and lapatinib, are not effective in the treatment of gastroesophageal cancer [131, 132]. Similarly, maintenance of trastuzumab beyond first-line progression and higher than standard doses of trastuzumab are also not recommended [131, 133].

A single-arm study with 37 patients evaluated the activity of the addition of pembrolizumab to trastuzumab + chemotherapy in first-line treatment of HER2-positive metastatic oesophagogastric cancer patients [134]. The median progression-free survival was 13.0 months, median overall survival was 27.3 months and $91 \%$ of patients with measurable disease achieved overall response. Phase III trial of this combination compared to standard of care, KEYNOTE-811, is ongoing.

What are the recommended regimens for the treatment of second and subsequent lines for oesophageal squamous cell carcinoma?

\section{Recommendations}

- Patients with PD-L1 CPS $\geq 10$ squamous cell carcinoma may be treated with second-line pembrolizumab. EVIDENCE LEVEL I, RECOMMENDATION A

- Nivolumab may be used as second-line treatment of advanced squamous cell oesophageal cancer, regardless of biomarker expression. EVIDENCE LEVEL II, RECOMMENDATION B.

- Patients may receive second-line monotherapy with irinotecan or taxane for metastatic squamous cell carcinoma of the oesophagus. EVIDENCE LEVEL III, RECOMMENDATION B.

- Patients with preserved performance status and previously treated with two lines may receive subsequent treatment with active drugs not yet used. EVIDENCE LEVEL V, RECOMMENDATION C.

- Pembrolizumab may be indicated for second-line or subsequent therapy for MSI-H tumours. EVIDENCE LEVEL III, RECOMMENDATION A

- Larotrectinib should be considered in NTRK-gene fusion-positive patients. EVIDENCE LEVEL III, RECOMMENDATION A

There are only limited data on the efficacy of second-line chemotherapy for advanced oesophageal cancer. Therefore, there is no standard approach, and the choice of therapy regimen is eventually empirical.

The phase III KEYNOTE-181 study compared pembrolizumab (200 mg every 3 weeks) or the investigators' choice of chemotherapy (docetaxel, paclitaxel or irinotecan) as second-line therapy for patients with advanced squamous cell carcinoma or adenocarcinoma of the oesophagus or OGJ (Siewert type I) [135]. The primary outcome was overall survival in patients with squamous cell carcinoma, patients with tumours expressing PD-L1 CPS $\geq 10$, and all randomised patients. Among the 222 patients who had PD-L1 CPS $\geq 10$, pembrolizumab significantly improved median overall survival (9.3 versus 6.7 months) and overall response rate (22\% versus $6 \%$ ). There was also significant improvement in overall survival with pembrolizumab in squamous cell carcinoma subgroup (8.2 versus 7.1 months). Fewer patients had grade $3-5$ treatment-related adverse events with pembrolizumab compared to chemotherapy.

The role of nivolumab as second-line treatment of advanced squamous cell oesophageal carcinoma was evaluated in ATTRACTION-3 trial [136]. In this study, 419 patients who were refractory or intolerant to one previous fluoropyrimidine-based and platinum-based chemotherapy were randomised to receive either nivolumab (240 mg every 2 weeks) or investigator's choice of chemotherapy (paclitaxel 100 mg/ $\mathrm{m}^{2}$ per week for 6 weeks then 1 week off; or docetaxel $75 \mathrm{mg} / \mathrm{m}^{2}$ every 3 weeks). $96 \%$ of enrolled patients were Asian. Overall survival was significantly improved in the nivolumab group (median 10.9 months versus 8.4 months; $\mathrm{HR}=0.77 ; 95 \% \mathrm{Cl}=0.62-0.96 ; p=0.019$ ). The benefit was seen irrespective of tumour PD-L1 expression (TPS), as evaluated by Dako 28-8 pharmDx assay [136].

Le et al [77] evaluated the activity of pembrolizumab in a cohort of 78 patients with advanced mismatch repair-deficient cancers across 12 different tumour types, from which five had gastroesophageal primaries. Objective responses were observed in $53 \%$ of patients. Responses 
were durable, with median progression-free survival and overall survival still not reached. The activity of pembrolizumab in MSI-H tumours gave the drug the first approval of a tissue-site agnostic agent by Food and Drug Administration (FDA) [137].

Patients with NTRK fusion-positive tumours of different primary sites had a response rate of $75 \%$ after treatment with larotrectinib. The progression-free survival rate at 1 year was 55\%. Although exceptionally rare in oesophagogastric tumours, NTRK-fusion testing is recommended to identify eventual candidates to NTRK inhibitors [138].

Which regimens are recommended for the treatment of second and subsequent lines of oesophageal or OGJ adenocarcinoma?

\section{Recommendations}

- In the metastatic setting, patients with oesophageal or OGJ adenocarcinoma are usually treated similarly to patients with gastric adenocarcinoma.

- Second-line chemotherapy should be recommended for patients with good performance status (ECOG 0-1). EVIDENCE LEVEL I, RECOMMENDATION A.

- Paclitaxel associated with ramucirumab, when available, is recommended for patients with ECOG 0-1. EVIDENCE LEVEL II, RECOMMENDATION A.

- Patients with oesophageal adenocarcinoma and PD-L1 CPS $\geq 10$ may be treated with second-line pembrolizumab. EVIDENCE LEVEL II, RECOMMENDATION B.

- Monotherapy with ramucirumab, irinotecan or taxane are alternatives as second or later treatment of advanced oesophagogastric adenocarcinoma. EVIDENCE LEVEL II, RECOMMENDATION B.

- Third or later lines of chemotherapy may be used in patients with metastatic oesophagogastric adenocarcinoma, depending on previous regimens and performance status. EVIDENCE LEVEL IV, RECOMMENDATION C.

- Pembrolizumab may be used in the third-line or subsequent treatments of patients with ECOG 0 or 1 and PD-L1-positive gastric or OGJ adenocarcinoma. EVIDENCE LEVEL III, RECOMMENDATION A.

- Pembrolizumab is indicated for second or subsequent lines of treatment in patients with advanced gastric or OGJ adenocarcinoma and MSI not previously treated with checkpoint inhibitors, although this indication has not yet been approved in Brazil. EVIDENCE LEVEL III, RECOMMENDATION A.

- Larotrectinib should be considered in NTRK-gene fusion-positive patients. EVIDENCE LEVEL III, RECOMMENDATION A.

- Trastuzumab deruxtecan may be considered in trastuzumab-resistant HER2-positive OGJ adenocarcinoma, if available. EVIDENCE LEVEL II, RECOMMENDATION A.

See GTG gastric cancer consensus for discussion about chemotherapy, NTRK inhibitors, trastuzumab deruxtecan and immunotherapy in PD-L1 CPS $\geq 1$ or MSI-H patients [4].The aforementioned KEYNOTE-181 showed that second-line pembrolizumab increased overall survival over chemotherapy in patients with oesophageal carcinomas and PD-L1 CPS $\geq 10$. However, subgroup analysis identified that the benefit was mostly driven by squamous cell carcinoma patients. Second-line pembrolizumab in patients with adenocarcinoma and PD-L1 CPS $\geq 10$ is approved by Brazilian Health Regulatory Agency (ANVISA), but not by FDA [135].

\section{Oesophageal and OGJ cancer follow-up}

How should patients with oesophageal, OGJ and gastric cancer be followed-up after treatment with curative intent?

For patients with cancer of the oesophagus or OGJ, T1s or T1a treated with endoscopic resection or ablation: [139]UDE every 3 months in the first year and every 6 months in the second year. After this period, annual UDE for 5 years. EVIDENCE LEVEL IV, RECOMMENDATION B.

- Imaging exams are not recommended. EVIDENCE LEVEL V, RECOMMENDATION A.

- For patients with oesophageal or OGJ cancer, T1s or T1a treated with oesophagectomy:

- UDE should be carried out according to symptoms. EVIDENCE LEVEL V, RECOMMENDATION A.

- Imaging exams are not recommended. EVIDENCE LEVEL V, RECOMMENDATION A. 
For patients with oesophageal or OGJ cancer, T1bNO treated with chemoradiotherapy:

- UDE should be carried out every 6 months for the first 3 years. Repeat UDE only if clinically indicated. EVIDENCE LEVEL IV, RECOMMENDATION A;

- $\mathrm{CT}$ of the chest and abdomen can be considered every 6-12 months in the first three years, then if clinically indicated. EVIDENCE LEVEL V RECOMMENDATION C.

For patients with oesophageal or JEG cancer, $\mathrm{T} 2-4$ or $\mathrm{N}+$ treated with chemoradiotherapy:

- UDE may be carried out every 6 months for the first 3 years, then if clinically indicated. EVIDENCE LEVEL IV RECOMMENDATION A.

- CTs of the chest and abdomen can be considered every 6-12 months for the first 2 years. After this period, CT can be carried out annually until the fifth year. EVIDENCE LEVEL V RECOMMENDATION C.

For patients with oesophageal or OGJ cancer, $\mathrm{T} 2-4$ or $\mathrm{N}+$ treated with trimodal therapy:

- UDE may be carried out, if clinically indicated. EVIDENCE LEVEL V RECOMMENDATION A.

- $\mathrm{CT}$ of the chest and abdomen can be considered every 6-12 months for the first 2 years. After this period, CT may be carried out annually until the fifth year. EVIDENCE LEVEL V RECOMMENDATION C.

\section{Conclusion}

Scientific evidence must endorse decisions in daily medical practice. Cancer patients present complex requirements that are often difficult to be addressed by a single specialist. The GTG suggests a multidisciplinary approach and monitoring of patients with oesophageal and OGJ cancer. In line with this, GTG developed local specialist consensus guidelines on oesophageal and OGJ cancer. Nonetheless, the therapeutic choice of the physician must always prevail, considering the individuality of the patient.

\section{Funding source}

There were no funding sources for this project.

\section{Conflicts of interest}

Duilio R Rocha-Filho: personal fees from Bayer, Merck Serono and Servier.

Renata D'Alpino Peixoto: personal fees from Lilly and MSD.

Anelisa K Coutinho: personal fees from Amgen, Bayer, Roche, MSD, Merck Serono, Sanofi, Servier, Ipsen, Novartis and United Medical.

Juliana F M Rego: personal fees from Novartis, Bayer, Amgen and Ipsen.

Rachel Riechelmann: research grants from Libbs (gastric consensus only).

Rui F Weschenfelder: personal fees from Lilly, MSD and Roche.

Alexandre A Jacome: personal fees from Roche, Novartis, Zodiac and Pfizer. Research grants from Bayer.

Celso A L Mello: personal fees from Lilly, Merck Serono, MSD and Roche.

Gustavo S Fernandes: personal fees from BMS, Bayer and Roche. 
Roberto A Gil: personal fees from Amgen, Bayer, Lilly, Merck Serono, Roche, Sanofi and United Medical. Research grant from Amgen, Bayer, Merck and Roche.

Victor Hugo F Jesus: personal fees from United Medical.

\section{References}

1. Torre LA, Siegel RL, and Ward EM, et al (2016) Global cancer incidence and mortality rates and trends - an update Cancer Epidemiol Biomarkers Prev 25(1) 16-27 https://doi.org/10.1158/1055-9965.EPI-15-0578

2. INCA (2019) Estimativa 2020: Incidência de câncer no Brasil (Rio de Janeiro: Instituto Nacional de Câncer José Alencar Gomes Da Silva)

3. van Nistelrooij AMJ, van Marion R, and van ljcken WFJ, et al (2018) Germline variant in MSX1 identified in a Dutch family with clustering of Barrett's esophagus and esophageal adenocarcinoma Fam Cancer 17(3) 435-440 https://doi.org/10.1007/s10689-017-0054-2 PMCID: 5999157

4. D'Alpino Peixoto R, Rocha-Filho DR, and Weschenfelder RF, et al (2020) Brazilian Group of Gastrointestinal Tumours' consensus guidelines for the management of gastric cancer Ecancermedicalscience 141126 https://doi.org/10.3332/ecancer.2020.1126

5. Kim TJ, Kim HY, and Lee KW, et al (2009) Multimodality assessment of esophageal cancer: preoperative staging and monitoring of response to therapy Radiographics 29(2) 403-421 https://doi.org/10.1148/rg.292085106 PMID: 19325056

6. Van Westreenen HL, Westerterp M, and Bossuyt PMM, et al (2004) Systematic review of the staging performance of 18F-fluorodeoxyglucose positron emission tomography in esophageal cancer J Clin Oncol 22(18) 3805-3812 https://doi.org/10.1200/JCO.2004.01.083 PMID: 15365078

7. Chatterton BE, Ho Shon I, and Baldey A, et al (2009) Positron emission tomography changes management and prognostic stratification in patients with oesophageal cancer: results of a multicentre prospective study Eur J Nucl Med Mol Imaging 36(3) 354-361 https://doi. org/10.1007/s00259-008-0959-y

8. Downey RJ, Akhurst T, and Ilson D, et al (2003) Whole body 18FDG-PET and the response of esophageal cancer to induction therapy: results of a prospective trial J Clin Oncol 21(3) 428-432 https://doi.org/10.1200/JCO.2003.04.013 PMID: 12560430

9. Heeren PAM, Jager PL, and Bongaerts F, et al (2004) Detection of distant metastases in esophageal cancer with18F-FDG PET J Nucl Med 45(6) 980-987 PMID: 15181133

10. Van Vliet EPM, Heijenbrok-Kal MH, and Hunink MGM, et al (2008) Staging investigations for oesophageal cancer: a meta-analysis Br J Cancer 98(3) 547-557 https://doi.org/10.1038/sj.bjc.6604200 PMID: 18212745 PMCID: 2243147

11. Krill T, Baliss M, and Roark R, et al (2019) Accuracy of endoscopic ultrasound in esophageal cancer staging J Thorac Dis 11(Suppl 12) S1602-S1609 https://doi.org/10.21037/jtd.2019.06.50 PMID: 31489227 PMCID: 6702397

12. Puli SR, Reddy JBK, and Bechtold ML, et al (2008) Staging accuracy of esophageal cancer by endoscopic ultrasound: a meta-analysis and systematic review World J Gastroenterol 14(10) 147-1490 https://doi.org/10.3748/wjg.14.1479

13. Pouw RE, Heldoorn N, and Herrero LA, et al (2011) Do we still need EUS in the workup of patients with early esophageal neoplasia? A retrospective analysis of 131 cases Gastrointest Endosc 73(4) 662-668 https://doi.org/10.1016/j.gie.2010.10.046 PMID: 21272876

14. Catalano MF, Van Dam J, and Sivak MV (1995) Malignant esophageal strictures: staging accuracy of endoscopic ultrasonography Gas trointest Endosc 41(6) 535-539 https://doi.org/10.1016/S0016-5107(95)70186-9 PMID: 7672544

15. Sun F, Chen T, and Han J, et al (2015) Staging accuracy of endoscopic ultrasound for esophageal cancer after neoadjuvant chemotherapy: a meta-analysis and systematic review Dis Esophagus 28(8) 757-771 https://doi.org/10.1111/dote.12274 
16. Lambin P, Zindler J, and Vanneste B, et al (2015) Modern clinical research: How rapid learning health care and cohort multiple randomised clinical trials complement traditional evidence based medicine Acta Oncol 54(9) 1289-1300 https://doi.org/10.3109/02841 86X.2015.1062136 PMID: 26395528

17. Park CM, Goo JM, and Lee HJ, et al (2009) Tumors in the tracheobronchial tree: CT and FDG pet features Radiographics 29(1) 55-71 https://doi.org/10.1148/rg.291085126 PMID: 19168836

18. Riedel M, Stein HJ, and Mounyam L, et al (2000) Bronchoscopy in the preoperative staging of oesophageal cancer below the tracheal bifurcation: a prospective study Eur Respir J 16(1) 134-139 https://doi.org/10.1034/j.1399-3003.2000.16a24.x PMID: 10933099

19. Pfau PR and Kochman ML (2000) Pretreatment staging by endoscopic ultrasonography does not predict complete response to neoadjuvant chemoradiation in patients with esophageal carcinoma Gastrointest Endosc 88(5) 1184-1186 https://doi.org/10.1002/(sici)10970142(20000301)88:5<1184::aid-cncr31>3.3.co;2-d

20. Wallace MB, Hawes RH, and Sahai AV, et al (2000) Dilation of malignant esophageal stenosis to allow EUS guided fine- needle aspiration: safety and effect on patient management Gastrointest Endosc 51(3) 309-313 https://doi.org/10.1016/S0016-5107(00)70360-9 PMID: 10699776

21. Igreja A, Marinho B, and Felipe L, et al (2018) Profile of patients with esophageal cancer diagnosed between 2001 and 2010 in Brazil Rev Bras Cancerol 64(4) 471-477 https://doi.org/10.32635/2176-9745

22. Tustumi F, Takeda FR, and Kimura CMS, et al (2016) Esophageal carcionoma: is schamous cell different disease compared to adenocarcinoma? A transversal study in a quaternary high volume hospital in Brazil Arq Gastroenterol 53(1) 44-48 https://doi.org/10.1590/ S0004-28032016000100009 PMID: 27281504

23. Bosman F, Carneiro F, and Hruban R, et al (2010) WHO Classification of Tumors of Digestive System

24. Amin MB, Edge SB, and Greene FL, et al (2017) AJCC Cancer Staging Manual 8th edn (New York, NY: Springer)

25. Rice TW (2000) Clinical staging of esophageal carcinoma: CT, EUS, and PET Chest Surg Clin N Am10(3) 471-485 PMID: 10967751

26. Rice TW, Patil DT, and Blackstone EH 8th edition AJCC/UICC staging of cancers of the esophagus and esophagogastric junction: application to clinical practice Ann Cardiothorac Surg 6(2) 119-130 https://doi.org/10.21037/acs.2017.03.14 PMID: 28447000 PMCID: 5387145

27. College of American Pathologists (2017) Protocol for the Examination of Specimens from Patients with Carcinoma of the Esophagus (Northfield: College of American Pathologists)

28. The Royal College of Pathologists (2019) Dataset for the Histopathological Reporting of Oesophageal and Gastric Carcinoma 3rd edn (London: The Royal College of Pathologists)

29. Noble F, Lloyd MA, and Turkington R, et al (2017) Multicentre cohort study to define and validate pathological assessment of response to neoadjuvant therapy in oesophagogastric adenocarcinoma Br J Surg 104(13) 1816-1828 https://doi.org/10.1002/bjs.10627 PMID: 28944954 PMCID: 5725679

30. Philippron A, Bollschweiler E, and Kunikata A, et al (2016) Prognostic relevance of lymph node regression after neoadjuvant chemoradiation for esophageal cancer Semin Thorac Cardiovasc Surg 28(2) 549-558 https://doi.org/10.1053/j.semtcvs.2016.04.003

31. Greenstein AJ, Wisnivesky JP, and Litle VR (2008) Effect of local therapy for the treatment of superficial esophageal cancer in nonoperative candidates Dis Esophagus 21(8) 673-678 https://doi.org/10.1111/j.1442-2050.2008.00832.x PMID: 18459986

32. Ross JS (2009) Breast cancer biomarkers and HER2 testing after 10 years of anti-HER2 therapy Drug News Perspect 22(2) 93-106 https://doi.org/10.1358/dnp.2009.22.2.1334452 PMID: 19330168

33. Ross JS and McKenna BJ (2001) The HER-2/neu oncogene in tumors of the gastrointestinal tract Cancer Invest 19(5) 554-568 https:// doi.org/10.1081/CNV-100103852 PMID: 11458821 
34. Goodman KA, Hall N, and Bekaii-Saab TS, et al (2018) Survival outcomes from CALGB 80803 (Alliance): a randomized phase II trial of PET scan-directed combined modality therapy for esophageal cance J Clin Oncol 36(15) abst 4012. https://doi.org/10.1200/ JCO.2018.36.15_suppl.4012

35. Hofmann M, Stoss O, and Shi D, et al (2008) Assessment of a HER2 scoring system for gastric cancer: results from a validation study Histopathology 52(7) 797-805 https://doi.org/10.1111/j.1365-2559.2008.03028.x PMID: 18422971

36. Jouret-Mourin AHA, Kockx M, and Demetter PVCE (2011) Belgian guidelines for HER2 testing in gastric cancer Belg J Med Oncol 5(1) 14-22

37. Smyth EC, Wotherspoon A, and Peckitt C, et al (2017) Mismatch repair deficiency, microsatellite instability, and survival: an exploratory analysis of the Medical Research Council Adjuvant Gastric Infusional Chemotherapy (MAGIC) trial JAMA Oncol 3(9) 1197-1203 https://

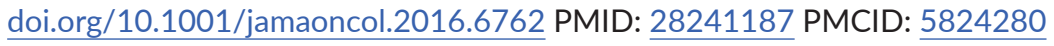

38. Polom K, Marano L, and Marrelli D, et al (2018) Meta-analysis of microsatellite instability in relation to clinicopathological characteristics and overall survival in gastric cancer Br J Surg 105(3) 159-167 https://doi.org/10.1002/bjs.10663

39. Yamashita K, Iwatsuki M, and Harada K, et al (2020) Prognostic impacts of the combined positive score and the tumor proportion score for programmed death ligand-1 expression by double immunohistochemical staining in patients with advanced gastric cancer Gastric Cancer 23(1) 95-104 https://doi.org/10.1007/s10120-019-00999-9

40. Penault-Llorca F, Rudzinski ER, and Sepulveda AR (2019) Testing algorithm for identification of patients with TRK fusion cancer J Clin Pathol 72(7) 460-467 https://doi.org/10.1136/jclinpath-2018-205679 PMID: 31072837 PMCID: 6589488

41. Takubo K, Aida J, and Sawabe M, et al (2007) Early squamous cell carcinoma of the oesophagus: the Japanese viewpoint Histopathology 51(6) 733-742 https://doi.org/10.1111/j.1365-2559.2007.02766.x PMID: 17617215

42. Axon A, Diebold MD, and Fujino M, et al (2005) Update on the Paris classification of superficial neoplastic lesions in the digestive tract Endoscopy 37(6) 570-578 https://doi.org/10.1055/s-2005-861352

43. (2003) The Paris endoscopic classification of superficial neoplastic lesions: esophagus, stomach, and colon Gastrointest Endosc 58(6 Suppl) S3-S43 https://doi.org/10.1016/S0016-5107(03)02159-X PMID: 14652541

44. Pimentel-Nunes P, Dinis-Ribeiro M, and Ponchon T, et al (2015) Endoscopic submucosal dissection: European Society of Gastrointestinal Endoscopy (ESGE) Guideline Endoscopy 47(9) 829-854 https://doi.org/10.1055/s-0034-1392882 PMID: 26317585

45. Badreddine RJ, Prasad GA, and Lewis JT, et al (2010) Depth of submucosal invasion does not predict lymph node metastasis and survival of patients with esophageal carcinoma Clin Gastroenterol Hepatol 8(3) 248-253 https://doi.org/10.1016/j.cgh.2009.11.016 PMCID: 2834861

46. Akutsu Y, Uesato M, and Shuto K, et al (2013) The overall prevalence of metastasis in T1 esophageal squamous cell carcinoma: a retrospective analysis of 295 patients Ann Surg 257(6) 1032-1038 https://doi.org/10.1097/SLA.0b013e31827017fc

47. Birkmeyer JD, Siewers AE, and Finlayson EVA, et al (2002) Hospital volume and surgical mortality in the United States N Engl J Med 346(15) 1128-1137 https://doi.org/10.1056/NEJMsa012337 PMID: 11948273

48. Birkmeyer JD, Stukel TA, and Siewers AE, et al (2003) Surgeon volume and operative mortality in the United States N Engl J Med 349(22) 2117-2127 https://doi.org/10.1056/NEJMsa035205 PMID: 14645640

49. Markar SR, Karthikesalingam A, and Thrumurthy S, et al (2012) Volume-outcome relationship in surgery for esophageal malignancy: systematic review and meta-analysis 2000-2011 J Gastrointest Surg 16(5) 1055-1063 https://doi.org/10.1007/s11605-011-1731-3

50. Metzger R, Bollschweiler E, and Vallböhmer D, et al (2004) High volume centers for esophagectomy: What is the number needed to achieve low postoperative mortality? Dis Esophagus 17(4) 310-314 https://doi.org/10.1111/j.1442-2050.2004.00431.x PMID: 15569369 
51. Lerut T, Coosemans W, and Decker G, et al (2005) Surgical techniques J Surg Oncol 92(3) 218-229 https://doi.org/10.1002/jso.20363 PMID: 16299783

52. Worrell SG (2020) Esophageal cancer and surgical margins: when a positive is a negative Ann Surg Oncol 27(5) $1316-1317$ https://doi. org/10.1245/s10434-019-08181-2 PMID: 31900810

53. Straatman J, van der Wielen N, and Cuesta MA, et al (2017) Minimally invasive versus open esophageal resection: three-year follow-up of the previously reported randomized controlled trial: the TIME trial Ann Surg 266(2) 232-236 https://doi.org/10.1097/ SLA.0000000000002171 PMID: 28187044

54. van der Sluis PC, van der Horst S, and May AM, et al (2019) Robot-assisted minimally invasive thoracolaparoscopic esophagectomy versus open transthoracic esophagectomy for resectable esophageal cancer: a randomized controlled trial Ann Surg 269(4) 621-630 https://doi.org/10.1097/SLA.0000000000003031

55. Mariette C, Markar SR, and Dabakuyo-Yonli TS, et al (2019) Hybrid minimally invasive esophagectomy for esophageal cancer N Engl J Med 380(2) 152-162 https://doi.org/10.1056/NEJMoa1805101 PMID: 30625052

56. Nagpal K, Ahmed K, and Vats A, et al (2010) Is minimally invasive surgery beneficial in the management of esophageal cancer? A metaanalysis Surg Endosc 24(7) 1621-1629 https://doi.org/10.1007/s00464-009-0822-7 PMID: 20108155

57. Dantoc M, Cox MR, and Eslick GD (2012) Evidence to support the use of minimally invasive esophagectomy for esophageal cancer: a meta-analysis Arch Surg 147(8) 768-776 https://doi.org/10.1001/archsurg.2012.1326 PMID: 22911078

58. Guo W, Ma X, and Yang S, et al (2016) Combined thoracoscopic-laparoscopic esophagectomy versus open esophagectomy: a metaanalysis of outcomes Surg Endosc 30(9) 3873-3881 https://doi.org/10.1007/s00464-015-4692-x

59. Sgourakis G, Gockel I, and Radtke A, et al (2010) Minimally invasive versus open esophagectomy: meta-analysis of outcomes Dig Dis Sci 55(11) 3031-3040 https://doi.org/10.1007/s10620-010-1153-1 PMID: 20186484

60. Agha FP, Gennis MA, and Orringer MB, et al (1986) Evaluation of response to preoperative chemotherapy in esophageal and gastric cardia cancer using biphasic esophagrams and surgical-pathologic correlation Am J Clin Oncol Cancer Clin Trials 9(3) 227-232 https:// doi.org/10.1097/00000421-198606000-00011

61. Ajani JA, Roth JA, and Putnam JB, et al (1995) Feasibility of five courses of pre-operative chemotherapy in patients with resectable adenocarcinoma of the oesophagus or gastrooesophageal junction Eur J Cancer 31A(5) 665-670 https://doi.org/10.1016/0959-8049(94)00318-Y PMID: 7640036

62. Ajani JA, Roth JA, and Ryan B, et al (1990) Evaluation of pre- and postoperative chemotherapy for resectable adenocarcinoma of the esophagus or gastroesophageal junction J Clin Oncol 8(7) 1231-1238 https://doi.org/10.1200/JCO.1990.8.7.1231 PMID: 2358838

63. Carey RW, Hilgenberg AD, and Choi NC, et al (1991) A pilot study of neoadjuvant chemotherapy with 5-fluorouracil and cisplatin with surgical resection and postoperative radiation therapy and/or chemotherapy in adenocarcinoma of the esophagus Cancer 68(3) 489-492 https://doi.org/10.1002/1097-0142(19910801)68:3<489::AID-CNCR2820680307>3.0.CO;2-M PMID: 2065268

64. Kies MS, Rosen ST, and Tsang T-K, et al (1987) Cisplatin and 5-fluorouracil in the primary management of squamous esophageal cancer Cancer 60(9) 2156-2160 https://doi.org/10.1002/1097-0142(19871101)60:9<2156::AID-CNCR2820600906>3.0.CO;2-G PMID: 3440225

65. Teniere P, Hay JM, and Fingerhut A, et al (1991) Postoperative radiation therapy does not increase survival after curative resection for squamous cell carcinoma of the middle and lower esophagus as shown by a multicenter controlled trial Surg Gynecol Obstet 173(2) 123-130 PMID: 1925862

66. Allum WH, Stenning SP, and Bancewicz J, et al (2009) Long-term results of a randomized trial of surgery with or without preoperative chemotherapy in esophageal cancer J Clin Oncol 27(30) 5062-5067 https://doi.org/10.1200/JCO.2009.22.2083 PMID: 19770374 
67. Cunningham D, Allum WH, and Stenning SP, et al (2006) Perioperative chemotherapy versus surgery alone for resectable gastroesophageal cancer N Engl J Med 355(1) 11-20 https://doi.org/10.1056/NEJMoa055531 PMID: 16822992

68. Kelsen DP, Winter KA, and Gunderson LL, et al (2007) Long-term results of RTOG trial 8911 (USA intergroup 113): a random assignment trial comparison of chemotherapy followed by surgery compared with surgery alone for esophageal cancer J Clin Oncol 25(24) 3719-3725 https://doi.org/10.1200/JCO.2006.10.4760 PMID: 17704421

69. Girling DJ, Bancewicz J, and Clark PI, et al (2002) Surgical resection with or without preoperative chemotherapy in oesophageal cancer: a randomised controlled trial Lancet 359(9319) 1727-1733 https://doi.org/10.1016/S0140-6736(02)08651-8

70. Ychou M, Boige V, and Pignon JP, et al (2011) Perioperative chemotherapy compared with surgery alone for resectable gastroesophageal adenocarcinoma: An FNCLCC and FFCD multicenter phase III trial J Clin Oncol 29(13) 1715-1721 https://doi.org/10.1200/ JCO.2010.33.0597 PMID: 21444866

71. Gebski V, Burmeister B, and Smithers BM, et al (2007) Survival benefits from neoadjuvant chemoradiotherapy or chemotherapy in oesophageal carcinoma: a meta-analysis Lancet Oncol 8(3) 226-234 https://doi.org/10.1016/S1470-2045(07)70039-6 PMID: 17329193

72. Bin WD, Zhang X, and Han HL, et al (2012) Neoadjuvant chemoradiotherapy could improve survival outcomes for esophageal carcinoma: a meta-analysis Dig Dis Sci 57(12) 3226-3233 https://doi.org/10.1007/s10620-012-2263-8

73. Apinop C, Puttisak P, and Preecha N (1994) A prospective study of combined therapy in esophageal cancer Hepatogastroenterology 41(4) 391-393 PMID: 7959579

74. Berger AC, Farma J, and Scott WJ, et al (2005) Complete response to neoadjuvant chemoradiotherapy in esophageal carcinoma is associated with significantly improved survival J Clin Oncol 23(19) 4330-4337 https://doi.org/10.1200/JC0.2005.05.017 PMID: 15781882

75. Bosset JF, Gignoux M, and Triboulet JP, et al (1997) Chemoradiotherapy followed by surgery compared with surgery alone in squamouscell cancer of the esophagus N Engl J Med 337(3) 161-167 https://doi.org/10.1056/NEJM199707173370304 PMID: 9219702

76. Burmeister B, Smithers M, and Gebski V, et al (2005) Surgery alone versus chemoradiotherapy followed by surgery for resectable cancer of the oesophagus: a randomised controlled phase III trial Lancet Oncol 6(9) 659-668 https://doi.org/10.1016/S1470-2045(05)70288-6 PMID: 16129366

77. Lee JL, Park SI, and Kim SB, et al (2004) A single institutional phase III trial of preoperative chemotherapy with hyperfractionation radiotherapy plus surgery versus surgery alone for resectable esophageal squamous cell carcinoma Ann Oncol 15(6) 947-954 https:// doi.org/10.1093/annonc/mdh219 PMID: 15151953

78. Nygaard K, Hagen S, and Hansen HS, et al (1992) Pre-operative radiotherapy prolongs survival in operable esophageal carcinoma: a randomized, multicenter study of pre-operative radiotherapy and chemotherapy. The second scandinavian trial in esophageal cancer World J Surg 16(6) 1104-1109 https://doi.org/10.1007/BF02067069 PMID: 1455880

79. Prise E Le, Etienne PL, and Meunier B, et al (1994) A randomized study of chemotherapy, radiation therapy, and surgery versus surgery for localized squamous cell carcinoma of the esophagus Cancer 73(7) 1779-1784 https://doi.org/10.1002/10970142(19940401)73:7<1779::AID-CNCR2820730702>3.0.CO;2-T PMID: 8137201

80. Tepper J, Krasna MJ, and Niedzwiecki D, et al (2008) Phase III trial of trimodality therapy with cisplatin, fluorouracil, radiotherapy, and surgery compared with surgery alone for esophageal cancer: CALGB $9781 \mathrm{~J}$ Clin Oncol 26(7) 1086-1092 https://doi.org/10.1200/ JCO.2007.12.9593 PMID: 18309943 PMCID: 5126644

81. Urba SG, Orringer MB, and Turrisi A, et al (2001) Randomized trial of preoperative chemoradiation versus surgery alone in patients with locoregional esophageal carcinoma J Clin Oncol 19(2) 305-313 https://doi.org/10.1200/JC0.2001.19.2.305 PMID: 11208820

82. Walsh TN, Noonan N, and Hollywood D, et al (1996) A comparison of multimodal therapy and surgery for esophageal adenocarcinoma N Engl J Med 335(7) 462-467 https://doi.org/10.1056/NEJM199608153350702 PMID: 8672151 
83. Van Hagen P, Hulshof MCCM, and Van Lanschot JJB, et al (2012) Preoperative chemoradiotherapy for esophageal or junctional cancer N Engl J Med 366(22) 2074-2084 https://doi.org/10.1056/NEJMoa1112088 PMID: 22646630

84. Shapiro J, van Lanschot JJB, and Hulshof MCCM, et al (2015) Neoadjuvant chemoradiotherapy plus surgery versus surgery alone for oesophageal or junctional cancer (CROSS): long-term results of a randomised controlled trial Lancet Oncol 16(9) 1090-1098 https:// doi.org/10.1016/S1470-2045(15)00040-6 PMID: 26254683

85. Cooper JS, Guo MD, and Herskovic A, et al (1999) Chemoradiotherapy of locally advanced esophageal cancer: long-term follow-up of a prospective randomized trial (RTOG 85-01) J Am Med Assoc 281(17) 1623-1627 https://doi.org/10.1001/jama.281.17.1623

86. Stahl M, Walz MK, and Stuschke M, et al (2009) Phase III comparison of preoperative chemotherapy compared with chemoradiotherapy in patients with locally advanced adenocarcinoma of the esophagogastric junction J Clin Oncol 27(6) 851-856 https://doi. org/10.1200/JCO.2008.17.0506 PMID: 19139439

87. Kranzfelder M, Schuster T, and Geinitz H, et al (2011) Meta-analysis of neoadjuvant treatment modalities and definitive non-surgical therapy for oesophageal squamous cell cancer Br J Surg 98(6) 768-783 https://doi.org/10.1002/bjs.7455 PMID: 21462364

88. Sjoquist KM, Burmeister BH, and Smithers BM, et al (2011) Survival after neoadjuvant chemotherapy or chemoradiotherapy for resectable oesophageal carcinoma: an updated meta-analysis Lancet Oncol 12(7) 681-692 https://doi.org/10.1016/S1470-2045(11)70142-5 PMID: 21684205

89. Al-Batran SE, Homann N, and Pauligk C, et al (2019) Perioperative chemotherapy with fluorouracil plus leucovorin, oxaliplatin, and docetaxel versus fluorouracil or capecitabine plus cisplatin and epirubicin for locally advanced, resectable gastric or gastro-oesophageal junction adenocarcinoma (FLOT4): a randomized, phase 2/3 trial Lancet 393(10184) 1948-1857 https://doi.org/10.1016/SO1406736(18)32557-1 PMID: 30982686

90. Ando N, lizuka T, and Ide H, et al (2003) Surgery plus chemotherapy compared with surgery alone for localized squamous cell carcinoma of the thoracic esophagus: a Japan Clinical Oncology Group Study - JCOG9204 J Clin Oncol 21(24) 4592-4596 https://doi. org/10.1200/JCO.2003.12.095 PMID: 14673047

91. Ando N, Kato H, and Igaki H, et al (2012) A randomized trial comparing postoperative adjuvant chemotherapy with cisplatin and 5-fluorouracil versus preoperative chemotherapy for localized advanced squamous cell carcinoma of the thoracic esophagus (JCOG9907) Ann Surg Oncol 19(1) 68-74 https://doi.org/10.1245/s10434-011-2049-9

92. Kitagawa Y, Uno T, and Oyama T, et al (2019) Esophageal cancer practice guidelines 2017 edited by the Japan Esophageal Society: part 1 Esophagus 16(1) 1-24 https://doi.org/10.1007/s10388-018-0641-9 PMCID: 6510883

93. Kelly RJ, Ajani JA, and Kuzdzal J, et al (2020) Adjuvant nivolumab in resected esophageal or gastroesophageal junction cancer (EC/ GEJC) following neoadjuvant chemoradiation therapy (CRT): first results of the CheckMate 577 study Ann Oncol 31(suppl_4) S1142S1215 https://doi.org/10.1016/j.annonc.2020.08.2299

94. Byfield JE (1989) 5-Fluorouracil radiation sensitization - a brief review Invest New Drugs 7(1) 111-116 https://doi.org/10.1007/ BF00178197 PMID: 2661479

95. Lawrence TS, Tepper JE, and Blackstock AW (1997) Fluoropyrimidine-radiation interactions in cells and tumors Semin Radiat Oncol 7(4) 260-266 https://doi.org/10.1016/S1053-4296(97)80024-0

96. Creane M, Seymour CB, and Colucci S, et al (1999) Radiobiological effects of docetaxel (Taxotere): a potential radiation sensitizer Int J Radiat Biol 75(6) 731-737 https://doi.org/10.1080/095530099140078

97. Chen AY, Choy H, and Rothenberg ML (1999) DNA topoisomerase I-targeting drugs as radiation sensitizers Oncology 13(10 Suppl 5) 39-46 PMID: 10550825

98. Smith TJ, Ryan LM, and Douglass HO, et al (1998) Combined chemoradiotherapy vs. radiotherapy alone for early stage squamous cell carcinoma of the esophagus: a study of the Eastern Cooperative Oncology Group Int J Radiat Oncol Biol Phys 42(2) 269-276 https://doi. org/10.1016/S0360-3016(98)00232-6 PMID: 9788404 
99. Wong RK and Malthaner R (2010) Combined chemotherapy and radiotherapy (without surgery) compared with radiotherapy alone in localized carcinoma of the esophagus Cochrane Database Syst Rev (1) CD002092 https://doi.org/10.1002/14651858.cd002092.pub3

100.De-Ren S (1989) Ten-year follow-up of esophageal cancer treated by radical radiation therapy: analysis of 869 patients Int J Radiat Oncol Biol Phys 16(2) 329-334 https://doi.org/10.1016/0360-3016(89)90324-6

101.Okawa T, Kita M, and Tanaka M, et al (1989) Results of radiotherapy for inoperable locally advanced esophageal cancer Int J Radiat Oncol Biol Phys 17(1) 49-54 https://doi.org/10.1016/0360-3016(89)90369-6 PMID: 2745207

102.al-Sarraf M, Martz K, and Herskovic A, et al (1997) Progress report of combined chemoradiotherapy versus radiotherapy alone in patients with esophageal cancer: an intergroup study J Clin Oncol 15(1) 277-284 https://doi.org/10.1200/JCO.1997.15.1.277 PMID: 8996153

103. Herskovic A, Martz K, and al-Sarraf M, et al (1992) Combined chemotherapy and radiotherapy compared with radiotherapy alone in patients with cancer of the esophagus N Engl J Med 326(24) 1593-1598 https://doi.org/10.1056/NEJM199206113262403 PMID: 1584260

104. Bedenne L, Michel P, and Bouché O, et al (2007) Chemoradiation followed by surgery compared with chemoradiation alone in squamous cancer of the esophagus: FFCD $9102 \mathrm{~J}$ Clin Oncol 25(10) 1160-1168 https://doi.org/10.1200/JCO.2005.04.7118 PMID: 17401004

105.Stahl M, Stuschke M, and Lehmann N, et al (2005) Chemoradiation with and without surgery in patients with locally advanced squamous cell carcinoma of the esophagus J Clin Oncol 23(10) 2310-2317 https://doi.org/10.1200/JCO.2005.00.034 PMID: 15800321

106. Martin-Richard M, Díaz Beveridge R, and Arrazubi V, et al (2016) SEOM Clinical Guideline for the diagnosis and treatment of esophageal cancer (2016) Clin Transl Oncol 18(12) 1179-1186 https://doi.org/10.1007/s12094-016-1577-y PMID: 27900538 PMCID: 5138258

107.Sudo K, Taketa T, and Correa AM, et al (2013) Locoregional failure rate after preoperative chemoradiation of esophageal adenocarcinoma and the outcomes of salvage strategies J Clin Oncol 31(34) 4306-4310 https://doi.org/10.1200/JCO.2013.51.7250 PMID: 24145339 PMCID: 3837091

108. Markar S, Gronnier C, and Duhamel A, et al (2015) Salvage surgery after chemoradiotherapy in the management of esophageal cancer: is it a viable therapeutic option? J Clin Oncol 33(33) 3866-3873 https://doi.org/10.1200/JCO.2014.59.9092 PMID: 26195702

109.Sudo K, Xiao L, and Wadhwa R, et al (2014) Importance of surveillance and success of salvage strategies after definitive chemoradiation in patients with esophageal cancer J Clin Oncol 32(30) 3400-3405 https://doi.org/10.1200/JCO.2014.56.7156 PMID: 25225435 PMCID: 4195852

110.Booka E, Haneda R, and Ishii K, et al (2020) Appropriate candidates for salvage esophagectomy of initially unresectable locally advanced T4 esophageal squamous cell carcinoma Ann Surg Oncol 27(9) 3163-3170 https://doi.org/10.1245/s10434-020-08440-7 PMID: 32314159

111.Swisher SG, Wynn P, and Putnam JB, et al (2002) Salvage esophagectomy for recurrent tumors after definitive chemotherapy and radiotherapy J Thorac Cardiovasc Surg 123(1) 175-183 https://doi.org/10.1067/mtc.2002.119070 PMID: 11782772

112. Nishimura M, Daiko H, and Yoshida J, et al (2007) Salvage esophagectomy following definitive chemoradiotherapy Gen Thorac Cardiovasc Surg 55(11) 461-464 https://doi.org/10.1007/s11748-007-0157-z PMID: 18049854

113.Markar SR, Karthikesalingam A, and Penna M, et al (2014) Assessment of short-term clinical outcomes following salvage esophagectomy for the treatment of esophageal malignancy: systematic review and pooled analysis Ann Surg Oncol 21(3) 922-931 https://doi. org/10.1245/s10434-013-3364-0

114.Kato K, Sun J, and Shah M (2020) Pembrolizumab plus chemotherapy versus chemotherapy as first-line therapy in patients with advanced esophageal cancer: the phase 3 KEYNOTE-590 study Ann Oncol 31(suppl 4) S1142-S1215 https://doi.org/10.1016/j. annonc.2020.08.2298 
115.Cunningham D, Starling N, and Rao S, et al (2008) Capecitabine and oxaliplatin for advanced esophagogastric cancer N Engl J Med 358(1) 36-46 https://doi.org/10.1056/NEJMoa073149 PMID: 18172173

116.Al-Batran SE, Hartmann JT, and Probst S, et al (2008) Phase III trial in metastatic gastroesophageal adenocarcinoma with fluorouracil, leucovorin plus either oxaliplatin or cisplatin: a study of the Arbeitsgemeinschaft Internistische Onkologie J Clin Oncol 26(9) 14351442 https://doi.org/10.1200/JCO.2007.13.9378 PMID: 18349393

117.Guimbaud R, Louvet C, and Ries P, et al (2014) Prospective, randomized, multicenter, phase III study of fluorouracil, leucovorin, and irinotecan versus epirubicin, cisplatin, and capecitabine in advanced gastric adenocarcinoma: a French intergroup (Fédération Francophone de Cancérologie Digestive, Fédération Nationale des Centres de Lutte Contre le Cancer, and Groupe Coopérateur Multidisciplinaire en Oncologie) study J Clin Oncol 32(31) 3520-3526 https://doi.org/10.1200/JCO.2013.54.1011 PMID: 25287828

118.Ajani JA, Baker J, and Pisters PWT, et al (2002) CPT-11 plus cisplatin in patients with advanced, untreated gastric or gastroesophageal junction carcinoma: results of a phase II study Cancer 94(3) 641-646 https://doi.org/10.1002/cncr.10279 PMID: 11857295

119.Ilson DH, Saltz L, and Enzinger P, et al (1999) Phase II trial of weekly irinotecan plus cisplatin in advanced esophageal cancer J Clin Oncol 17(10) 3270-3275 https://doi.org/10.1200/JCO.1999.17.10.3270 PMID: 10506629

120.Burtness B, Gibson M, and Egleston B, et al (2009) Phase II trial of docetaxel-irinotecan combination in advanced esophageal cancer Ann Oncol 20(7) 1242-1248 https://doi.org/10.1093/annonc/mdn787 PMID: 19429872 PMCID: 2699385

121.Enzinger PC, Burtness B, and Hollis D, et al (2010) CALGB 80403/ECOG 1206: a randomized phase II study of three standard chemotherapy regimens (ECF, IC, FOLFOX) plus cetuximab in metastatic esophageal and GE junction cancer J Clin Oncol 34(23) 2736-2742 https://doi.org/10.1200/JCO.2015.65.5092

122. Van Cutsem E, Moiseyenko VM, and Tjulandin S, et al (2006) Phase III study of docetaxel and cisplatin plus fluorouracil compared with cisplatin and fluorouracil as first-line therapy for advanced gastric cancer: a report of the V25 study group J Clin Oncol 24(31) 4991-4997 https://doi.org/10.1200/JCO.2006.06.8429 PMID: 17075117

123.Shah MA, Janjigian YY, and Stoller R, et al (2015) Randomized multicenter phase II study of modified docetaxel, cisplatin, and fluorouracil (DCF) versus DCF plus growth factor support in patients with metastatic gastric adenocarcinoma: a study of the US gastric cancer consortium J Clin Oncol 33(33) 3874-3879 https://doi.org/10.1200/JC0.2015.60.7465 PMID: 26438119

124.Van Cutsem E, Boni C, and Tabernero J, et al (2015) Docetaxel plus oxaliplatin with or without fluorouracil or capecitabine in metastatic or locally recurrent gastric cancer: a randomized phase II study Ann Oncol 26(1) 149-156 https://doi.org/10.1093/annonc/mdu496

125.Al-Batran SE, Pauligk C, Homann N, et al (2013) The feasibility of triple-drug chemotherapy combination in older adult patients with oesophagogastric cancer: a randomised trial of the Arbeitsgemeinschaft Internistische Onkologie (FLOT65+) Eur J Cancer 49(4) 835-842 https://doi.org/10.1016/j.ejca.2012.09.025

126. Hall P, Swinson D, and Waters J (2019) Optimizing chemotherapy for frail and elderly patients (pts) with advanced gastroesophageal cancer (aGOAC): the GO2 phase III trial J Clin Oncol 37(15) 4006 https://doi.org/10.1200/JC0.2019.37.15_suppl.4006

127. Moehler M, Shitara K, and Garrido M (2020) Nivolumab (nivo) plus chemotherapy (chemo) versus chemo as first-line (1L) treatment for advanced gastric cancer/gastroesophageal junction cancer (GC/GEJC)/esophageal adenocarcinoma (EAC): first results of the CheckMate 649 study Ann Oncol 31 S1142-S1215 https://doi.org/10.1016/j.annonc.2020.08.2296

128.Boku N, Ryu MH, and Oh D, et al (2020) Nivolumab plus chemotherapy versus chemotherapy alone in patients with previously untreated advanced or recurrent gastric/gastroesophageal junction (G/GEJ) cancer: ATTRACTION-4 (ONO-4538-37) study Ann Oncol 31(Suppl. 4) S1142-S1215 https://doi.org/10.1016/j.annonc.2020.08.2297

129.Shitara K, Van Cutsem E, and Bang YJ, et al (2020) Efficacy and safety of pembrolizumab or pembrolizumab plus chemotherapy vs chemotherapy alone for patients with first-line, advanced gastric cancer: the KEYNOTE-062 phase 3 randomized clinical trial JAMA Oncol 6(10) 1571-1580 https://doi.org/10.1001/jamaoncol.2020.3370 PMID: 32880601 PMCID: 7489405 
130.Bang YJ, Van Cutsem E, and Feyereislova A, et al (2010) Trastuzumab in combination with chemotherapy versus chemotherapy alone for treatment of HER2-positive advanced gastric or gastro-oesophageal junction cancer (ToGA): a phase 3, open-label, randomised controlled trial Lancet 376(9742) 687-697 https://doi.org/10.1016/S0140-6736(10)61121-X PMID: 20728210

131. Tabernero J, Hoff PM, and Shen L, et al (2017) Pertuzumab (P) + trastuzumab (H) + chemotherapy (CT) for HER2-positive metastatic gastric or gastro-oesophageal junction cancer (mGC/GEJC): final analysis of a Phase III study (JACOB) Ann Oncol 28(Suppl 5) v209v268 https://doi.org/10.1093/annonc/mdx369

132. Hecht JR, Bang YJ, and Qin SK, et al (2016) Lapatinib in combination with capecitabine plus oxaliplatin in human epidermal growth factor receptor 2-positive advanced or metastatic gastric, esophageal, or gastroesophageal adenocarcinoma: TRIO-013/LOGiC - a randomized phase III trial J Clin Oncol 34(5) 443-451 https://doi.org/10.1200/JCO.2015.62.6598

133.Al-Shamsi HO, Fahmawi Y, and Dahbour I, et al (2016) Continuation of trastuzumab beyond disease progression in HER2-positive metastatic gastric cancer: the MD Anderson experience J Gastrointest Oncol 7(4) 499-505 https://doi.org/10.21037/jgo.2016.06.16 PMID: 27563438 PMCID: 4963369

134.Janjigian YY, Maron SB, and Chatila WK, et al (2020) First-line pembrolizumab and trastuzumab in HER2-positive oesophageal, gastric, or gastro-oesophageal junction cancer: an open-label, single-arm, phase 2 trial Lancet Oncol 21(6) 821-831 https://doi.org/10.1016/ S1470-2045(20)30169-8 PMID: 32437664

135.Shah MA, Adenis A, and Enzinger PC, et al (2019) Pembrolizumab versus chemotherapy as second-line therapy for advanced esophageal cancer: phase 3 KEYNOTE-181 study J Clin Oncol 37(suppl 15) 4010 https://doi.org/10.1200/JCO.2019.37.15_suppl.4010

136. Kato K, Cho BC, and Takahashi M, et al (2019) Nivolumab versus chemotherapy in patients with advanced oesophageal squamous cell carcinoma refractory or intolerant to previous chemotherapy (ATTRACTION-3): a multicentre, randomised, open-label, phase 3 trial Lancet Oncol 20(11) 1506-1517 https://doi.org/10.1016/S1470-2045(19)30626-6 PMID: 31582355

137.Le DT, Durham JN, and Smith KN, et al (2017) Mismatch repair deficiency predicts response of solid tumors to PD-1 blockade Science (80- ) 357(6349) 409-413 https://doi.org/10.1126/science.aan6733

138.Drilon A, Laetsch TW, and Kummar S, et al (2018) Efficacy of larotrectinib in TRK fusion-positive cancers in adults and children N Engl J Med 378(8) 731-739 https://doi.org/10.1056/NEJMoa1714448 PMID: 29466156 PMCID: 5857389

139.Shaheen NJ, Falk GW, and lyer PG, et al (2016) ACG clinical guideline: diagnosis and management of Barrett's esophagus Am J Gastroenterol 111(1) 30-50 https://doi.org/10.1038/ajg.2015.322 